\title{
DRIPs and the Dividend Pay Date Effect
}

September 2013

\author{
Henk Berkman \\ University of Auckland Business School \\ Auckland, New Zealand \\ h.berkman@auckland.ac.nz
}

Paul D. Koch*

School of Business

University of Kansas

Lawrence, KS 66045

pkoch@ku.edu

*Corresponding author. This version is preliminary. We acknowledge the helpful comments of Ferhat Akbas, Robert DeYoung, David Emanuel, Kathleen Fuller, Brad Goldie, Ted Juhl, Michal Kowalik, Joe Lan, Dimitris Margaritis, Alastair Marsden, Felix Meschke, Nada Mora, Peter Phillips, David Solomon, Ken Spong, Jide Wintoki, and seminar participants at the Annual Conferences of the Society of Financial Studies Finance Cavalcade, the Financial Management Association, and the Southern Finance Association, as well as the University of Auckland, the University of Canterbury, the University of Kansas, and the Federal Reserve Bank of Kansas City. We also acknowledge the excellent research assistance of Aaron Andra, Suzanna Emelio, and Evan Richardson. Please do not quote without permission. 


\title{
DRIPs and the Dividend Pay Date Effect
}

\begin{abstract}
On the day that dividends are paid we find a significant positive abnormal return that is completely reversed over the following days. This dividend pay date effect has strengthened since the 1970s, and is concentrated among high dividend yield stocks that offer dividend reinvestment plans (DRIPs). It is larger for DRIP stocks that face greater limits to arbitrage and for stocks with greater participation in their DRIPs. Profits from a trading strategy that exploits this price behavior are economically significant, and are correlated with market sentiment, transaction costs, the dividend premium, and the VIX.
\end{abstract}

JEL Classification: D82, G14, G19.

Key Words: market efficiency, anomaly, dividend reinvestment plan, retail investors, sentiment, transaction costs, short sales, institutional ownership. 


\section{Introduction}

Many studies examine stock prices around the dividend announcement day or the exdividend date. These events might contain value-relevant news associated with a dividend surprise, or evoke trading to capture dividends. ${ }^{1}$ In contrast, when the dividend pay date arrives, there is no tax-motivated trading and no new information about the amount or timing of this distribution. Nevertheless, we find striking evidence of a predictable price increase around the pay date that is completely reversed over the following days. This temporary inflation is concentrated among firms with a high dividend yield and dividend reinvestment plans (DRIPs). ${ }^{2}$

The fact that there is no new information on the pay date, combined with the prevalence of DRIPs among U.S. stocks, creates an ideal setting to test the price pressure hypothesis. ${ }^{3}$ Ogden (1994) is the first to exploit these features, and examines the dividend pay date effect for U.S. stocks during the period, 1962 - 1989. He finds a small but significant mean abnormal return of 7 basis points (bp) on the pay date, which accumulates to $20 \mathrm{bp}$ over the following three days. However, he finds no significant price reversal after the pay date, and thus concludes that his evidence does not support the temporary price pressure hypothesis.

Figure 1 reproduces the analysis of Ogden (1994), using an expanded sample of all dividend-paying stocks from 1975 - 2009. This figure shows that the temporary inflation around the pay date has grown in magnitude each decade since the 1970s, and is accompanied by a similar spike in trading volume. For the two quintiles with the highest dividend yield, the mean

\footnotetext{
1 DeAngelo, DeAngelo, and Skinner (2009) review this literature.

2 Company-sponsored DRIPs give investors the opportunity to automatically reinvest their dividend income into more shares of the firm, without incurring brokerage fees and sometimes at a discount. 3 Other events that have been studied to test price pressure are more likely to have information content. Examples include block sales, secondary distributions, and changes in the S\&P 500 Index. Studies of block sales and secondary distributions include Scholes (1972), Holthausen, Leftwich, and Mayers (1990), and Mikkelson and Partch (1986). Studies of changes in the S\&P 500 Index include Harris and Gurel (1986), Schleifer (1986), Beneish and Whaley (1996), Kaul, Mehrotra, and Morck (2000), and Chen, Noronha, and Singal (2004). Hartzmark and Solomon (2013) analyze temporary price pressure in the month that dividends are predicted.
} 
abnormal return on the pay date $(\mathrm{AR}(0))$ has increased from $12 \mathrm{bp}$ in the 1970s (Panel A) to 40 bp in the first decade of the new millennium (Panel D). This recent decade also reveals several significant negative price spikes after day +1 , indicating a reversal that offsets the temporary inflation. In addition, for the recent decade, we find a significant price spike on day -3 , suggesting that some shareholders may buy additional shares three days before the pay date, and pay for these shares with the dividend income received on day 0 (Odgen, 1994, Yadav, 2010). ${ }^{4}$

The main goal of this paper is to explore how the pay date effect varies across stocks, with a particular emphasis on the role of company-sponsored DRIPs. We extend the analysis of Ogden by separately analyzing the behavior of DRIP firms versus non-DRIP firms during the period from 1996 through 2009. We focus on this recent period because it reveals the greatest price pressure in Figure 1, and because we have lists of firms with DRIPs for this time frame.

Figure 2 provides a first glance at our main results. Here we examine the price patterns around the dividend pay date for two portfolios: all dividend-paying stocks, and a subset of high dividend yield stocks that are hard to arbitrage. ${ }^{5}$ Panels A and B plot the abnormal returns (ARs) and cumulative abnormal returns (CARs) for the subset of DRIP stocks in each portfolio, while Panels C and D plot the analogous ARs and CARs for the subset of non-DRIP stocks.

Panel A of Figure 2 reveals that the abnormal returns for these two portfolios of DRIP stocks are significantly positive on days $-3,0$, and +1 , and significantly negative on day +2 as well as several subsequent days. In addition, these ARs are significantly larger in magnitude for the second portfolio of high yield DRIP stocks that are hard to arbitrage. Panel B shows that the highest CAR for each portfolio is attained on day +1 , before reversing toward zero on subsequent days. For the second portfolio, the mean $\mathrm{AR}(0)$ is $85 \mathrm{bp}$, and the CAR reaches a peak that

4 The three-day settlement period for U.S. stocks became effective with SEC Rule 15c6-1, in July 1995. 5 The second portfolio includes the subset of all dividend-paying stocks each quarter that are in the top $40 \%$ by dividend yield, the bottom $40 \%$ by institutional ownership, and the top $40 \%$ by bid ask spread. 
exceeds 1 percent on day +1 . It is noteworthy that the series of negative ARs following day +1 accumulate to offset the entire price spike from this event. Thus the price reversal completely offsets the temporary inflation around the pay date for these portfolios of DRIP stocks.

Panels C and D of Figure 2 reveal that the analogous portfolios of non-DRIP stocks also display significant temporary inflation around the pay date. However, these ARs and CARs are much smaller in magnitude. For example, for the second portfolio of high yield non-DRIP stocks that are hard to arbitrage, the CAR reaches a maximum of just $37 \mathrm{bp}$ on day $+1 .^{6}$

We further explore the role of company-sponsored DRIPs and confirm the findings above by examining a matched sample of DRIP and non-DRIP stocks, and by using regression analysis. We also investigate cross-sectional variation in the demand and supply of shares around the pay date. This analysis shows that the pay date effect: (i) increases with greater demand due to greater DRIP participation, and (ii) induces a greater supply of shares by attracting short sellers.

Finally, we examine the performance of several trading strategies that prescribe holding certain portfolios of DRIP stocks on their respective pay dates (i.e., buy at the close on day -1 and sell at the close on day 0). Across all quarters in the sample period, 1996 - 2009, this strategy generates a mean abnormal return of $31 \mathrm{bp}$ per day for all DRIP stocks, 58 bp per day for DRIP stocks with a high dividend yield, and 92 bp per day for high yield DRIP stocks that are hard to arbitrage. The quarterly averages of these daily streams of abnormal profits $(A R(0))$ are positive in at least 50 of the 56 quarters in our sample. In addition, they are significantly related to time series movements in market sentiment, transaction costs, the dividend premium, and the VIX. ${ }^{7}$

6 One potential reason for this significant (albeit smaller) price spike for non-DRIP stocks is that retail brokerage houses also offer their clients the opportunity to reinvest dividends automatically, even for stocks that have no company-sponsored DRIP. In addition, some shareholders might reinvest their dividend income on their own. 7 To put the economic significance of these results in perspective, the performance of our second strategy (58 bp per day) accumulates to $12 \%$ per month. In comparison, the momentum anomaly returns about $1 \%$ per month, and the dividend premium anomaly returns 41 bp per month (Jegadeesh and Titman, 2001, Hartzmark and Solomon, 2013). 
Additional robustness tests provide further support for the role of DRIPs behind the pay date effect. For example, we show that these average price patterns for DRIP stocks are not due to outliers, since quarterly medians display similar behavior. We also find that the mean $\operatorname{AR}(0)$ is stable when we do not adjust for market movements, and when we adjust for risk in a FamaFrench framework. In addition, we further establish the economic significance of these results by showing that the quarterly average net profits generated from our trading strategies range from 7 bp to 30 bp per day, after subtracting the closing bid-ask spread from each firm's daily $\operatorname{AR}(0)$.

This paper contributes to the body of work that explores the price pressure hypothesis, by investigating an ideal setting where buying pressure stems from a perfectly predictable noninformation event (see footnote 3). In doing so, it explores the role of a widely used tool to implement a popular investing strategy, DRIPs, in influencing investor behavior and stock prices. It also contributes to the anomalies literature by providing evidence of predictable temporary inflation that has become stronger rather than weaker over time (Schwert, 2003, and McLean and Pontiff, 2012). Furthermore, and also in contrast to most other anomalies, we show that the pay date effect is not limited to small stocks that are subject to high information asymmetry. Companies with DRIPs tend to be large, with high institutional ownership, low spreads, and low volatility (Boehmer and Kelly, 2009, and Chordia et al., 2011). Finally, this paper adds to the literature on limits to arbitrage by showing that, while the temporary inflation around the pay date is actively exploited by short sellers, their activity is insufficient to eliminate this price pressure (Mitchell, Pulvino, and Stafford, 2002, and Stambaugh, Yu, and Yuan, 2012).

The remainder of the paper proceeds as follows. Section II reviews the limited academic literature involving DRIPs. Section III describes the implementation of DRIPs and discusses our data. Section IV presents our main results, by documenting the average patterns in abnormal 
returns around the pay date for the subsets of DRIP stocks versus non-DRIP stocks in different portfolios. Section V further explores the role of DRIPs by analyzing cross-sectional variation in the demand or supply of shares around the pay date. Section VI examines the profits of several trading strategies that exploit the pay date effect. A final section summarizes and concludes.

\section{Review of Literature on Dividend Reinvestment Plans}

The use of DRIPs expanded greatly in the 1970s (Pettway and Malone, 1973), but these plans have attracted relatively little research in the academic literature. Hansen, Pinkerton, and Keown (1985), Peterson, Peterson, and Moore (1987), and Scholes and Wolfson (1989) discuss the implications of DRIPs for shareholder wealth. Dhillon, Lasser, and Ramirez (1992), Finnerty (1989), and Scholes and Wolfson (1989) examine firms' use of DRIPs to raise capital, and conclude that DRIPs can help to mitigate the adverse price effects of new equity issues. Chiang, Frankfurter, and Kosedag (2005) examine the implications of DRIPs for dividend policy.

Ogden (1994) was the first to examine price pressure around the dividend pay date. He finds evidence of a small price impact that averages roughly $7 \mathrm{bp}$ on the pay date, which is somewhat larger for stocks with DRIPs. However, he finds no evidence of a reversal. Moreover, he relies on a published list of firms with DRIPs for just two years, 1984 and 1990, forcing him to make assumptions about which firms likely had DRIPs throughout the decade of the 1980s.

Two other working papers also explore price pressure around the pay date. Blouin and Cloyd (2005) investigate price changes around dividend pay dates for closed-end funds during the years, 1988 to 2003 . They claim that most of these funds have DRIPs with high participation rates. They find a significant price increase around the pay date, but no significant reversal. Yadav (2010) examines price changes around dividend pay dates over the years, 1997 to 2008. Using an incomplete list of 300 DRIP stocks, he finds that the mean abnormal return on the pay 
date is larger for his sample of DRIP stocks, compared to all stocks. In addition, similar to the result in Panel D of Figure 2, he documents a significant abnormal return three days before the pay date, and attributes this price spike to shareholders who buy more shares on day -3 , and use their dividend income to settle the trades three days later. He then focuses the remainder of his paper on potential microstructure determinants of this price spike on day -3 .

\section{Transfer Agents, DRIP Participation, and the Data}

\section{III.A. Transfer Agents and the Administration of Company-Sponsored DRIPs,}

Firms commonly enlist a transfer agent to manage the ownership record for all investors who trade the company's shares. Transfer agents ensure that all ownership rights are properly allocated to the shareholders of record, including voting rights, the right to new shares issued from stock splits, stock dividends or rights offerings, and the right to cash dividends. Firms also typically rely on their transfer agent to administer company-sponsored DRIPs.

Details regarding the implementation of each company-sponsored DRIP vary across firms, and are communicated to investors through a prospectus filed with the SEC, or a document distributed by the firm or the transfer agent. Two transfer agents that manage a substantial portion of all DRIPs sponsored by U.S. companies are Wells Fargo Shareowner Services and Computershare Trust Company. These two transfer agents have made DRIP documents available on their own web sites for a sizable number of their affiliated companies. ${ }^{8}$

This DRIP documentation typically describes three important features about the purchase of shares involved in the DRIP: (i) how the shares are to be purchased, (ii) when the shares are to be purchased, and (iii) what purchase price is to be charged to DRIP participants. First, each quarter the company will direct the transfer agent to either purchase newly issued shares from the

8 The web site of Computershare is https://www-us.computershare.com/investor/plans/planslist.asp?stype=drip, and the web site for Wells Fargo is https://www.shareowneronline.com/UserManagement/DisplayCompany.aspx. 
company, or purchase existing shares in the open market. Second, if the transfer agent is told to purchase shares in the open market, it is typically directed to purchase the shares "as soon as possible after receiving the funds." This common wording implies a fairly strong incentive for transfer agents to purchase shares in the open market on the dividend pay date (as soon as the dividend funds are received), in order to avoid litigation regarding any potential breach of fiduciary duty. Third, the price applied to every DRIP participant is typically the trade-weighted average price that applies to all shares bought to satisfy the DRIP if shares are purchased on the open market, or the closing price on the pay date if newly issued shares are purchased from the company. Appendix A provides excerpts from the DRIP documents for two firms. These documents describe the responsibilities of the transfer agent, and demonstrate the relevant details common in these plans

\section{III.B. DRIP Participation and the Number of Shareholders of Record}

We conjecture that the existence and implementation of company-sponsored DRIPs is a major force behind the pay date effect documented in this study. In designing tests of this conjecture, we are limited by the fact that no firm-specific data are available on the participation rates in company-sponsored DRIPs, or the shareholdings of DRIP participants. ${ }^{9}$ Given this limitation, we test this conjecture several ways in our main analysis, by separately examining the divergent behavior of firms with and without company-sponsored DRIPs. In addition, in our extended analysis of the role of DRIPs, we develop a firm-specific proxy for DRIP participation rates based on the number of shareholders of record for a firm. This proxy is motivated below.

\footnotetext{
9 We have had many conversations with companies, transfer agents, and retail brokerage houses to request data on firm-specific DRIP participation rates, the shareholdings of DRIP participants, and the timing and pricing of purchases made in the implementation of DRIPs. None of the entities we communicated with were willing to share any data or discuss their implementation of DRIPs, with many expressing a concern about the risk of litigation.
} 
The shares of firms with no company-sponsored DRIP are normally held in "street name" in retail brokerage accounts. This means that the shares are registered in the name of the brokerage firm through which the stock is bought, rather than the investor who purchased the stock. In this case, all communication between the company and the investor is routed through the broker. This practice gives the brokerage house control over details involving shareholder rights for their retail customers, and reduces the cost of providing brokerage services. The typical brokerage house charges a substantial fee to retail clients who ask to become shareholders of record, in order to discourage such requests. Thus, a few retail brokerage houses commonly operate as the shareholders of record on behalf of their numerous investors in non-DRIP stocks.

In contrast, firms with company-sponsored DRIPs routinely require an individual investor to become the shareholder of record in order to participate in their DRIP. This requirement helps to grow and stabilize retail ownership, and results in all communication being made directly between the firm and its shareholders. It also enables the firm's transfer agent to administer the DRIP directly to the firm's shareholders.

As a result of this struggle between firms and retail brokerage houses to control the record of ownership, the official number of shareholders (Compustat annual variable, CSHR) drastically understates the true number of investors for the typical firm. However, we find that the average number of shareholders is significantly larger for firms with company-sponsored DRIPs than for firms without DRIPs. This difference presumably reflects participation in DRIPs. Furthermore, we argue that cross-sectional variation in the number of shareholders across DRIP firms reveals information about firm-specific DRIP participation rates. We exploit this feature of DRIPs to generate a proxy for DRIP participation based on the actual number of shareholders at a firm, relative to the number expected (predicted) at other DRIP firms with similar attributes. 


\section{III.C. Data and Variables}

We use daily returns for all NYSE, AMEX, and NASDAQ common stocks (CRSP share code 10 or 11) during the period, July 1975 through December 2009. We analyze benchmarkadjusted abnormal returns to measure stock price performance (see Daniel, Grinblatt, Titman, and Wermers, 1997). The abnormal return is defined as the difference between the actual return on a stock and the return on an equally weighted portfolio of all firms in the same size and bookto-market quintiles. For each stock, we obtain annual portfolio assignments into size and bookto-market quintiles from Russ Wermers's website. ${ }^{10}$

We obtain the pay dates of all quarterly cash dividend distributions from CRSP $($ distcd $=$ 1200 - 1299). If a pay date is on a weekend, we recognize that the dividend payment will occur on the next business day. We keep all quarterly dividend events for which: (a) the number of days between the ex-dividend day and the pay date is at least 10 and no more than 45; (b) the number of days between the ex-dividend day and the record date is at least 2 and no more than 7 ; and (c) there are at least 20 days between a firm's consecutive dividend pay dates. These screens help to ensure that we ignore events with coding errors, and reduce the impact of ex-dividend price effects on the pay date price effect. ${ }^{11}$

For the years, 1996 - 2002, we have also obtained annual lists of firms with companysponsored DRIPs from the American Association of Individual Investors (AAII) annual publications on firms with DRIPs. For the subsequent years, 2003 - 2009, we obtained quarterly lists of DRIP firms using the AAII Stock Investor Pro web site. The AAII annual publications for the earlier years, 1996 - 2002, also provide information about certain features of these DRIPs. For example, for this sub-period, $25 \%$ of all DRIPs charged a fee for participation, while $7 \%$

10 Portfolio assignments for NYSE, AMEX, and NASDAQ stocks from CRSP are available since 1975, based on the approach in Wermers (2003), at http://www.smith.umd.edu/faculty/rwermers/ftpsite/Dgtw/coverpage.htm. 11 These screens eliminate 11,729 quarterly dividend payments out of the 299,813 events in the sample since 1975 . 
offered the opportunity to reinvest dividends at a discount of $1 \%$ to $5 \%$ below the market price. ${ }^{12}$

We analyze the following dependent variables, which represent abnormal returns measured over six different portions of the 21-day event window, $(-10,+10)$, covering the two weeks before and after the pay date. The timing of these six measures is dictated by the evidence in Figure 2, which indicates significant positive abnormal returns on days $-3,0$, and +1 , which are followed by a series of smaller but significant negative abnormal returns in the ensuing days.

\section{Dependent variables:}

1) $\mathrm{AR}(-3)=$ abnormal return on day -3 , three days before the pay date;

2) $\operatorname{AR}(0)=$ abnormal return on the dividend pay date;

3) $\operatorname{CAR}(0,+1)=$ cumulative abnormal return over days 0 and +1 ;

4) $\mathrm{CAR}(+2,+5)=$ cumulative abnormal return over days +2 through +5 ;

5) $\operatorname{CAR}(+2,+10)=$ cumulative abnormal return over days +2 through +10 ;

6) $\operatorname{CAR}(0,+10)=$ cumulative abnormal return over days 0 through +10 ; where $A R(t)=$ abnormal benchmark-adjusted return for the stock on day t relative to the dividend pay date (i.e., day 0 ), using the equally weighted benchmark return based on firms in the same size and book-to-market quintiles.

\section{Explanatory variables:}

1) DRIP = 1 if the firm has a company-sponsored DRIP, or 0 otherwise;

2) Size = the firm's daily market capitalization averaged over days -10 through -6 , where daily market capitalization is taken from CRSP;

3) Div_Yield = the firm's percentage dividend yield, computed as the cash dividend amount from CRSP divided by the firm's daily closing stock price, multiplied by 100 , and averaged over days -10 through -6 ;

4) Pct_INST = the percentage of total shares outstanding owned by institutional investors for the quarter, taken from $13 \mathrm{~F}$ filings;

5) Spread = the daily closing bid-ask spread, as a percentage of the daily closing price, taken from CRSP, and averaged over days -10 through $-6 ;^{13}$

12 In analysis not reported here, we find no evidence that the existence or magnitude of a fee or a discount affects the pay date effect, for the $25 \%$ of DRIP firms that charge a fee, or the $7 \%$ of DRIP firms that offer a discount. 13 Chung and Zhang (2013) show that the CRSP-based spread is highly correlated with the TAQ-based spread across stocks, using data from 1993 through 2009. Their results indicate that the simple CRSP-based spread can effectively be used in lieu of the TAQ-based spread in academic research that focuses on cross-sectional analysis. 
6) Log_HiLo = the intraday percentage stock return volatility, measured as the natural log of the ratio of the daily high and low prices multiplied by 100, taken from CRSP, and averaged over days -10 through -6 ;

7) CSHR = the (annual) number of shareholders of record, taken from Compustat;

8) Firm_Age $=$ the number of quarters since the firm first appeared on CRSP.

The relevant explanatory variables are known at least one week prior to the pay date. Thus, the results in this paper lead to predictive trading strategies that can easily be implemented. ${ }^{14}$

We examine three portfolios of stocks each quarter that vary in terms of dividend yield and the limits to arbitrage that they face. These portfolios are generated by first independently sorting all dividend-paying stocks each quarter according to their: (i) dividend yield, (ii) institutional ownership, and (iii) bid-ask spread. Then we construct portfolios I - III, as follows:

I (All Stocks): All dividend-paying stocks each quarter;

II (High_DY): Top 40\% of dividend-paying stocks each quarter by dividend yield;

III (Hard_Arb): Top 40\% of dividend-paying stocks each quarter by dividend yield, bottom $40 \%$ by institutional ownership, and top $40 \%$ by spread. $^{15}$

\section{Main Results: The Pay Date Effect}

\section{IV.A. The Average Pay Date Effect and Firm Characteristics for Portfolios I - III}

Table 1 provides the mean abnormal returns for different time frames around the dividend pay date for portfolios I - III, as well as descriptive statistics for the average firm characteristics in these portfolios. Each panel presents results for a different portfolio of stocks, with and without DRIPs. Panel A gives the results for all Stocks (I), while Panels B and C provide the analogous results for the High_DY portfolio (II) and the Hard_Arb portfolio (III).

14 Computing the average daily values of Size, Div_Yield, Spread, and Log_HiLo over days -10 through -6 ensures that we measure these firm attributes close to the dividend pay date (on day 0 ). We have also analyzed these firm attributes over different time frames before or after the event window, with similar results.

15 Other studies that use institutional ownership or transaction costs to examine the influence of limits to arbitrage on stock return performance include Asquith et al. (2005), Berkman et al. (2009), Berkman et al. (2012), Boehme et al. (2006), Diether et al. (2002), Nagel (2005), and Sadka and Scherbina (2007). 
In every Panel of Table 1 we present five sets of means and t-ratios for: (i) all stocks in that portfolio, (ii) DRIP stocks, (iii) non-DRIP stocks, (iv) the difference of means across DRIP stocks and non-DRIP stocks, and (v) the analogous results for a subset of matched pairs of DRIP firms versus non-DRIP firms in every portfolio. The subset of matched pairs from each portfolio is generated every quarter by a logistic regression in which propensity matching is based on the following four firm characteristics: Log_Size, Div_Yield, Pct_Inst, and Spread. These attributes regularly enter the quarterly logistic regressions with significant coefficients, while Log_HiLo is rarely significant and is thus omitted from the matching scheme.

The means reported in Table 1 are computed by first calculating the cross-sectional average for each variable every quarter, and second computing the time series mean of these quarterly cross-sectional averages. The standard error of each time series mean is then used to generate a t-test of the null hypothesis that each mean or mean difference is zero. ${ }^{16}$

First consider the mean abnormal returns around the pay date for all dividend-paying stocks, in columns (1) and (2) of Panel A in Table 1. Results indicate that an average of 1,418 U.S. stocks pay cash dividends each quarter. These stocks have a mean daily abnormal return three days before the pay date, $\mathrm{AR}(-3)$, of $8 \mathrm{bp}$, a mean $\mathrm{AR}(0)$ of $19 \mathrm{bp}$, and a mean $\mathrm{CAR}(0,+1)$ of $27 \mathrm{bp}$. This price increase is completely reversed over the following two weeks, with a mean CAR $(+2,+10)$ of -36 bp. All these mean ARs and CARs are significantly different from zero. Combining the $\operatorname{CAR}(0,+1)$ and the reversal, $\operatorname{CAR}(+2,+10)$, we obtain a $\operatorname{CAR}(0,+10)$ of $-9 \mathrm{bp}$, which is not significantly different from zero ( $\mathrm{t}$-ratio $=-0.7$ ). Together, this evidence supports the price pressure hypothesis, indicating a significant temporary increase in prices in the two days around the dividend pay date which is completely reversed over the following two weeks.

16 Table B.1 in Appendix B repeats the analysis in Table 1, but provides the time series mean of the quarterly crosssectional medians for each variable. Results are generally robust, indicating that our evidence is not due to outliers. 
The remaining columns of Panel A in Table 1 compare the behavior of all DRIP stocks versus all non-DRIP stocks. This comparison indicates that the temporary price pressure on the pay date is significantly larger in magnitude for firms with DRIPs (see AR(0) in columns 3 through 7)). The additional rows in Panel A reveal that the average DRIP firm is significantly larger in size, and tends to have a larger dividend yield, greater institutional ownership, smaller spreads, lower stock return volatility, a larger number of shareholders, and greater firm age.

The matched pairs reported in column (8) and (9) control for these differences in firm characteristics. As a result, column (10) indicates that the mean differences in dividend yield and spread are no longer significant across matched pairs. On the other hand, the mean differences in institutional ownership and size remain significantly different from zero, although small in magnitude. We also find that the matched set of DRIP stocks have a mean $A R(0)$ of $31 \mathrm{bp}$, which is significantly larger than the mean $\mathrm{AR}(0)$ of $12 \mathrm{bp}$ for the matched set of non-DRIP stocks. In addition, consistent with our earlier discussion, the mean (median) number of shareholders (CSHR) is significantly larger for DRIP stocks than for non-DRIP stocks. For the matched sample, the median DRIP firm has 6,863 shareholders and the median non-DRIP firm has 2,619 shareholders. Finally DRIP stocks tend to be older than the matched non-DRIP stocks.

Panels B and C of Table 1 give analogous results for the successively smaller portfolios with a higher dividend yield (II) and greater limits to arbitrage (III). As we proceed to Panels B and $\mathrm{C}$, the price run-up and reversal around the pay date grow larger in magnitude, and their mean differences across DRIP versus non-DRIP stocks become larger and more significant. The other relative attributes of DRIP firms versus non-DRIP firms from Panel A are fairly stable across the successive portfolios. It is noteworthy that, in contrast to many other anomalies, this pay date effect is not limited to small stocks that are subject to high information asymmetry. In 
each panel of Table 1, the subset of DRIP firms in each portfolio tend to be larger and older, with more shareholders, higher institutional ownership, smaller spreads, and lower volatility.

We again note that non-DRIP firms also display significant, albeit smaller, temporary price pressure around the pay date. This result may be due to shareholders who reinvest their dividend income on their own, or through participation in DRIPs offered by brokerage houses that also offer DRIPs to their retail clients, even for firms with no company-sponsored DRIP.

In every Panel of Table 1, we also present the mean abnormal return on the ex-dividend date, along with the mean difference between the abnormal return on the pay date versus that on the ex-date. ${ }^{17}$ For each subset of DRIP stocks in Panels A - C, the mean AR(0) on the pay date is significantly larger than the mean abnormal return on the ex-date. In contrast, for each subset of non-DRIP stocks, the mean $\mathrm{AR}(0)$ on the pay date is significantly smaller than that on the exdate. We also note that the mean abnormal return on the ex-date for DRIP stocks tends to be smaller than that for non-DRIP stocks (see column 7 in Table 1). This evidence indicates that the dividend pay date receives greater price pressure for DRIP stocks, while the ex-date is subject to greater price pressure for non-DRIP stocks. However, this difference seems to be partially associated with different firm characteristics across the two subsamples, since it diminishes for our pairs of firms matched by firm characteristics (see column 10). Together, these results reinforce the importance of DRIPs as a major force behind the dividend pay date effect.

\section{IV.B. Correlations across Abnormal Returns around the Pay Date for Portfolios I - III}

Table 2 presents the average correlations across the abnormal return measures around the pay date $(\mathrm{AR}(-3), \mathrm{AR}(0)$, and $\mathrm{CAR}(0,+1))$ and the measures of subsequent reversal $(\mathrm{CAR}(+2,+5)$ and $\mathrm{CAR}(+2,+10))$. Similar to Table 1 , each quarter we first compute every pairwise correlation

17 Hartzmark and Solomon (2013) provide evidence of temporary price pressure during the month that dividends are expected, which is followed by a reversal in the following month. They focus on the abnormal returns around the ex-dividend date, and do not consider the pay date effect or the impact of DRIPs on their results. 
across all stocks in each portfolio, I - III, as well as across the subsets of DRIP stocks or nonDRIP stocks in each portfolio. We then calculate the time series mean of every pairwise correlation across all quarters, and present the results in Panels A - C for portfolios I - III, respectively. The standard error of the time series mean is again used to test the null hypothesis that every mean correlation is zero. Pearson correlations are presented above the diagonal and Spearman correlations appear below the diagonal.

First consider the correlations involving AR(-3). Table 2 reveals only weak evidence that $\mathrm{AR}(-3)$ is correlated with the price spike around the pay date $(\operatorname{AR}(0)$ or $\operatorname{CAR}(0,+1))$, or the subsequent reversal $(\mathrm{CAR}(+2,+5)$ or $\mathrm{CAR}(+2,+10))$ for any portfolio. In addition, there is no tendency for the correlations involving AR(-3) to be larger for DRIP stocks compared with nonDRIP stocks. This outcome is not surprising since the explanation for this price spike proposed by Ogden (1994) and Yadav (2010), involving a 3-day settlement for buying additional shares, applies to shareholders of both DRIP stocks and non-DRIP stocks.

Next consider the correlations between the relative magnitudes of the price inflation around the pay date $(\operatorname{AR}(0)$ or $\operatorname{CAR}(0,+1))$ and the subsequent reversal $(\mathrm{CAR}(+2,+5$ or CAR $(+2,+10))$, highlighted in the shaded areas of Table 2 . These results indicate that the abnormal returns around the pay date are significantly negatively correlated with the cumulative abnormal returns over the following two weeks, for each portfolio. Furthermore, the magnitude of these negative correlations increases as we consider the progressively finer subsets of stocks with a higher dividend yield and greater limits to arbitrage, in the successive portfolios I - III. These results reinforce our evidence in Table 1, to provide further support for a systematic tendency for stock prices to increase around the pay date and reverse over the following two weeks, consistent with the temporary price pressure hypothesis. 


\section{Further Exploration of the Role of DRIPs behind the Pay Date Effect}

This section examines the association between the demand or supply of shares and the pay date effect. First we analyze how cross-sectional variation in demand may influence the magnitude of this temporary price pressure, by constructing a firm-specific proxy for DRIP participation rates and relating this proxy to $\operatorname{AR}(0)$ and $\operatorname{CAR}(0,+1)$. Second, we investigate how the pay date effect influences the supply of shares by attracting short sellers around the pay date.

\section{V.A. Demand for Shares, DRIP Participation, and the Pay Date Effect}

In this section we first propose a firm-specific proxy for DRIP participation rates based on the firm's number of shareholders. We then examine whether firms with greater demand for shares around the pay date, through greater DRIP participation, tend to have a larger pay date effect $(\mathrm{AR}(0)$ and $\mathrm{CAR}(0,+1))$. We begin by specifying the following model that describes the relation between the number of shareholders of record for a firm and certain firm characteristics:

$$
\begin{aligned}
\log \_C S H R_{\text {in }}=\alpha_{0} & +\alpha_{1} \text { Firm_Age }_{\text {in }}+\alpha_{2} \text { Log_Size }_{\text {in }}+\alpha_{3} \text { Div_Yield }_{\text {in }} \\
& +\alpha_{4} \text { Pct_Inst }_{\text {in }}+\alpha_{5} \text { Spread }_{\text {in }}+\alpha_{6} \text { Log_Hilo }_{\text {in }}+\varepsilon_{\text {in }} .
\end{aligned}
$$

This specification follows the convention in previous efforts to model determinants of CSHR, which take the natural log of both CSHR and firm size in order to mitigate the positive skewness inherent in these two variables. ${ }^{18}$

We estimate Equation (1) for the cross-section of either DRIP firms or non-DRIP firms each quarter. This approach enables our proxy to reflect how DRIP participation rates vary, not only in the cross-section, but also across quarters. The left two columns in Table 3 present the Fama-MacBeth mean coefficients for this model, applied each quarter to the subsets of all DRIP

18 For example, see Grullon, Kanatas, and Weston (2004) and Larkin, Leary, and Michaely (2013). 
stocks and all non-DRIP stocks, separately. The third column presents the differences in the respective mean coefficients across DRIP firms versus non-DRIP firms.

For both subsets of DRIP stocks and non-DRIP stocks, the mean coefficients in the first two columns of Table 3 indicate a significantly larger number of shareholders for a firm with greater age, larger size, higher dividend yield, lower institutional ownership, a higher spread, and greater volatility. Furthermore, the third column indicates that the impact of firm age on the number of shareholders is significantly smaller for DRIP firms relative to non-DRIP firms. In contrast, the third column also reveals that the mean coefficients for firm size, dividend yield, and institutional ownership are significantly larger in magnitude for the subset of DRIP firms. ${ }^{19}$

We use the actual and fitted values from Equation (1) each quarter, to construct our proxy for firm-specific DRIP participation rates, as follows:

$$
\text { DRIP_Part }{ }_{\text {in }}=\left(\text { Actual Value of } \log _{-} \mathrm{CSHR}_{\text {in }} / \text { Fitted Value of Log_CSHR }{ }_{\text {in }}\right) \text {. }
$$

This proxy is generated separately for the subsets of firms with and without DRIPs each quarter. It captures the actual number of shareholders for each DRIP (or non-DRIP) firm, relative to the number expected at other DRIP (or non-DRIP) firms with similar attributes.

We argue that this proxy contains relevant information about DRIP participation rates for the subset of DRIP firms, while it should be uninformative for the subset of non-DRIP firms. That is, when the number of shareholders (Log_CSHR) at a DRIP firm exceeds (or falls short of) that predicted by Equation (1) for other DRIP firms with similar characteristics, this excess (or shortfall) is likely to reflect greater (or lower) participation in the firm's DRIP. In contrast, this proxy should be meaningless for non-DRIP firms in terms of its relation to the pay date effect.

19 The Chow Test at the bottom of the third column in Table 3 verifies that the set of all coefficients from a panel regression for Equation (1) is significantly different for DRIP stocks versus non-DRIP stocks. 
Ceterus paribus, we expect that a higher participation rate in a firm's DRIP reflects greater demand for shares, and should thus be associated with a larger pay date effect. We test this prediction by specifying a model that includes DRIP_Part in $_{\text {in }}$ and other firm characteristics from Equation (1) as potential determinants of abnormal returns around the pay date, as follows:

$$
\begin{aligned}
{\left[\operatorname{AR}(0)_{\text {in }} \text { or CAR }(0,+1)_{\text {in }}\right]=\beta_{0} } & +\beta_{1} \text { DRIP_Part }_{\text {in }}+\beta_{2} \text { Log_Size }_{\text {in }}+\beta_{3} \text { Div_Yield }_{\text {in }} \\
& +\beta_{4} \text { Pct_Inst }_{\text {in }}+\beta_{5} \text { Spread }_{\text {in }}+\beta_{6} \text { Log_HiLo }_{\text {in }}+v_{\text {in }} .
\end{aligned}
$$

Once again, we expect a positive coefficient for DRIP_Part $\left(\beta_{1}\right)$ when Equation (2) is estimated for the set of DRIP firms, while $\beta_{1}$ should be zero for the set of non-DRIP firms.

The remaining columns in Table 3 present the results. We now estimate the panel in Equation (2) with standard errors clustered on the firm and the quarter of the dividend payment, applied separately to all DRIP stocks or all non-DRIP stocks. Results indicate that, for the subset of DRIP firms, a larger price spike on day 0 (or days 0 and +1 ) is significantly associated with a greater DRIP participation rate, as well as with lower institutional ownership or a larger dividend yield, spread, or volatility. In contrast, for non-DRIP firms, this DRIP participation proxy has no association with $\operatorname{AR}(0)$ or $\operatorname{CAR}(0,+1)$, as expected. Furthermore, the coefficient of DRIP_Part ${ }_{\text {in }}$ is significantly larger in magnitude for the subset of DRIP firms, relative to non-DRIP firms, as are the coefficients on two other firm characteristics in each set of results presented in Table $3{ }^{20}$

\section{V.B. Supply of Shares: Short Selling around the Pay Date}

If sophisticated investors try to exploit the temporary price increase around the pay date, then we would expect the volume of short selling to increase at the time of the largest positive price spikes, on days -3 and 0 . We investigate this possibility by examining daily movements in abnormal short volume (ASV) over the event window $(-10,+10)$. This variable is constructed

20 Once again, the Chow Test in column (3) verifies that the set of all coefficients from Equation (2) is significantly different across the subsets of DRIP stocks versus non-DRIP stocks. 
from Reg SHO data on daily short volume over the ten quarters covering the period, January 2005 through June 2007, as follows:

$$
\mathrm{ASV}_{\mathrm{itn}}=(\mathrm{SV} / \mathrm{TV})_{\mathrm{itn}}-\operatorname{Normal}(\mathrm{SV} / \mathrm{TV})_{\text {in }},
$$

where $(\mathrm{SV} / \mathrm{TV})_{\mathrm{itn}}=$ short volume as proportion of total volume for stock $\mathrm{i}$ on day $\mathrm{t}$ in quarter $\mathrm{n}$; and $\operatorname{Normal}(\mathrm{SV} / \mathrm{TV})_{\text {in }}=$ the mean of $(\mathrm{SV} / \mathrm{TV})_{\text {itn }}$ over days +11 through +30 , after day $0 .{ }^{21}$

We then examine the mean values of $\mathrm{ASV}_{\text {itn }}$ for all 21 days in the event window, $\mathrm{t}=$ $(-10,+10)$, for the subsets of DRIP stocks versus non-DRIP stocks in the portfolio of all dividend-paying stocks (I), and the portfolio of stocks with a high dividend yield (II). For a firm event to be included in this analysis, we require at least one day with non-zero shorting volume in the window $(+11,+30)$. This requirement reduces the sample to 6,451 events for portfolio I, and 2,261 events for portfolio II. ${ }^{22}$

As before, for every quarter we first compute the cross-sectional average of ASV(t) for each day, and then calculate the time series mean of these cross-sectional averages over the 10 quarters in the sample period for which we have short sales data. Likewise, the confidence intervals for the $\operatorname{ASV}(\mathrm{t})$ are obtained from the standard errors of the time series means, for the subset of DRIP stocks or non-DRIP stocks in portfolio II, for all 21 days in the event window. ${ }^{23}$

Results are plotted in Panels A and B of Figure 3 for the subsets of DRIP stocks and nonDRIP stocks, respectively, in portfolios I and II. For the two portfolios of DRIP stocks in Panel A, average abnormal short volume is positive on all but one day in the event window, and it is significantly greater than zero on days -3 and 0 . In addition, the magnitude of the spikes in

21 Our daily short-sales data are obtained from the self-regulatory organizations (SROs) that made tick data on short sales publicly available starting on January 2, 2005, as a result of the SEC's Regulation SHO. Short sales data for the NYSE are available through the TAQ database, and all other SROs make short sales data available on their websites. The end date for the regulation SHO data in our sample is July 1, 2007.

22 We do not present the results for the third portfolio of high yield stocks that are hard to arbitrage (III), because of small sample sizes (there are less than 10 events per quarter for the DRIP and non-DRIP subsets of this portfolio). 23 Similar to Figures 1 and 2, in Figure 3 the 95\% confidence interval for portfolio II is conservative for portfolio I. 
abnormal short volume on these two days increases somewhat as we move from the portfolio of all DRIP stocks (I) to the subset of high yield DRIP stocks (II). For portfolio II, the average abnormal short volume is $0.5 \%$ of total volume on day -3 , and $1 \%$ of total volume on day 0 .

For the analogous subsets of non-DRIP stocks analyzed in Panel B of Figure 3, we find no evidence of abnormal short selling around the pay date. The average abnormal short volume is small in magnitude for each day, and is never significantly greater than zero. This result is consistent with the lower temporary price inflation for these subsets of non-DRIP stocks documented in Figure 2 and Table 1. This evidence supports the view that short sellers try to exploit the predictable price spikes around the pay date for DRIP stocks, but their activity is insufficient to eliminate this temporary inflation.

\section{Strategies that Trade on this Price Pattern}

\section{VI.A. Quarterly Performance from Three Trading Strategies}

In this section we analyze the performance of three alternative trading strategies that attempt to profit from the price spike on day 0 . These strategies prescribe holding the subsets of DRIP stocks in each of our three portfolios, I - III, on their respective dividend pay dates. To implement each strategy, for every day in our sample, we first identify every DRIP stock in each portfolio that pays a dividend on the next day $(\mathrm{t})$. Then we prescribe buying the subset of all such DRIP stocks in each portfolio that pay dividends on the next day, and holding for 24 hours (i.e., buy at the close on day t-1 and sell at the close on day t). In addition, we assume a short position on an equivalent amount of the S\&P 500 index. This strategy earns the market-adjusted abnormal return, $\operatorname{AR}(0)_{\text {it }}$, for each DRIP stock that pays a dividend on any given day $\mathrm{t}^{24}$

\footnotetext{
24 Analysis of benchmark-adjusted abnormal returns yields similar results. In Appendix $\mathrm{C}$ we show that, for the two portfolios that are most interesting from a trading perspective (II. High_DY and III. Hard_Arb), the average price increase occurs gradually throughout the trading hours on day 0 . Thus, buying at the close on day -1 and selling at the close on day 0 captures the average $\operatorname{AR}(0)$. We have also analyzed two alternative strategies: (i) to hold each
} 
For every day $(t)$ in our sample period, we then compute the average across the $\operatorname{AR}(0)_{\text {it }}$ for all DRIP stocks in each portfolio (I - III) that pay dividends on that given date. The resulting mean values, $\operatorname{AR}(0)_{t}$, reflect a daily time series of one-day average abnormal "profits" for each strategy, for all days where at least one DRIP stock in each portfolio pays a dividend. Then, for every quarter $(n)$, we average these one-day mean abnormal returns, $\operatorname{AR}(0)_{t}$, across all days in the quarter where at least one DRIP stock pays a dividend. The results reflect a quarterly time series of average one-day abnormal returns, $\operatorname{AR}(0)_{n}$, from these three trading strategies. We then track this quarterly average $\mathrm{AR}(0)_{\mathrm{n}}$ for each subset of DRIP stocks from portfolios I - III, throughout all quarters of the sample period, 1996 to 2009.

\section{VI.B. Time Series Movements in Quarterly Abnormal Profits}

Figure 4 presents a time series plot of the quarterly mean one-day abnormal returns on the pay date, $\mathrm{AR}(0)_{\mathrm{n}}$, from applying these three trading strategies. For the portfolio of all dividendpaying DRIP stocks (I), the mean quarterly values of $\operatorname{AR}(0)_{n}$ are positive for 53 of the 56 quarters in the sample period, and the average one-day $\operatorname{AR}(0)_{n}$ across all quarters is $0.31 \%$. The portfolio of high dividend yield stocks (II) yields a similar stream of quarterly average profits that are positive for 53 quarters, and it generates a larger mean one-day $\mathrm{AR}(0)_{\mathrm{n}}$ of $0.58 \%$.

Finally, the average one-day profit stream from stocks that are hard to arbitrage (III) is somewhat more volatile, yet these profits are still positive in 50 quarters. This profit stream also generates a higher mean one-day $\operatorname{AR}(0)_{n}$ of $0.92 \%$ across all quarters in the sample.

Economic theory suggests that the magnitude of the quarterly average one-day $\operatorname{AR}(0)_{\mathrm{n}}$ from these trading strategies should be larger following periods when there is greater investor demand for dividend-paying stocks, or greater limits to arbitrage associated with the stocks held

portfolio of DRIP stocks on days 0 and +1 , earning $\operatorname{CAR}(0,+1)$, and (ii) to be long these stocks on days 0 and +1 , and then short over days $+2-+5$, earning $\operatorname{CAR}(0,+1)-\operatorname{CAR}(+2,+5)$. This analysis yields similar conclusions. 
in each strategy. This observation motivates the following regression model that specifies several potential determinants of the quarterly time series of average one-day profits for each strategy:

$$
\operatorname{AR}(0)_{\mathrm{n}}=\beta_{0}+\beta_{1} \text { Sentiment }_{\mathrm{n}-1}+\beta_{2} \text { Spread }_{\mathrm{n}-1}+\beta_{3} \operatorname{pdnd}_{\mathrm{n}-1}+\beta_{4} \operatorname{VIX}_{\mathrm{n}-1}+\varepsilon_{\mathrm{n}},
$$

where $\operatorname{AR}(0)_{\mathrm{n}}=$ quarterly average of the time series of mean one-day profits, $\operatorname{AR}(0)_{\mathrm{t}}$, for the portfolio of DRIP stocks from each strategy, across all days in quarter $\mathrm{n}$;

Sentiment $_{\mathrm{n}-1}=$ Baker and Wurgler (2006) sentiment index in quarter $\mathrm{n}-1 ;^{25}$

Spread $_{\mathrm{n}-1}=$ mean daily closing percentage spread for the DRIP stocks in the portfolio of high dividend yield stocks, across all days in quarter $\mathrm{n}-1 ;{ }^{26}$

$\operatorname{pdnd}_{\mathrm{n}-1}=$ value-weighted dividend premium in quarter n-1 (Baker and Wurgler, 2004);

VIX $_{n-1}=$ CBOE Volatility Index, averaged across the 3 months in quarter n-1.

First, the sentiment index of Baker and Wurgler is intended to capture the willingness of investors to trade at prices not justified by fundamentals. We expect that periods with relatively high market sentiment are likely to be followed by relatively high dividend reinvestment, and thus high price pressure on the pay date. Second, a larger average spread represents a limit to arbitrage that should reduce the willingness of arbitrageurs to trade against the pay date effect. Third, changes over time in the dividend premium reflect changing demand for dividend-paying stocks (Baker and Wurgler, 2004). We thus expect that periods with a stronger preference for dividend paying stocks are followed by a larger pay date effect. Finally, the VIX measures expectations about overall market volatility, so a larger VIX serves as a negative sentiment indicator that may be followed by less demand for these stocks, and thus a lower mean $\operatorname{AR}(0){ }^{27}$ Table 4 provides regression results for the DRIP stocks in portfolios I - III, respectively. First, the quarterly mean $\mathrm{AR}(0)_{\mathrm{n}}$ for each strategy is positively related to time series movements in market sentiment during the previous quarter, and significantly so for portfolios II and III.

25 Monthly data on the sentiment index of Baker and Wurgler (2006) are available on Jeff Wurgler's web site, along with the components of their index, such as pdnd. We aggregate these monthly data to form quarterly figures. 26 The daily percentage Spread $=($ Ask - Bid $) /(($ Ask + Bid $) / 2)$, where the closing Bid and Ask are taken from CRSP. 27 For further discussion of these issues involving limits to arbitrage and market sentiment, see Baker and Wurgler (2006, 2007), Kumar and Lee (2006), Sadka and Scherbina (2007), and Schleifer and Vishny (1997). 
Second, these profits have a significant positive association with transaction costs in the previous quarter, across all three strategies. Third, the $\operatorname{AR}(0)_{\mathrm{n}}$ is significantly influenced by the dividend premium in the previous quarter for the DRIP stocks in portfolio III. Finally, we find a negative association between the profitability of our strategies and the VIX from the previous quarter, which is significant for the DRIP stocks in portfolio III. We conclude from this analysis that, consistent with economic theory, time-variation in the magnitude of price pressure around the dividend pay date is significantly related to market sentiment, as well as limits to arbitrage.

\section{VI.C. Extended Tests on the Time Series of Profits}

Appendix D provides additional robustness tests to explore alternative possible explanations for our results, and to examine the sensitivity of these results to additional analyses.

\section{VI.C.1. Time Series Movements in Quarterly Actual Profits}

One conspicuous feature of Figure 4 is the large spike in the mean one-day $\operatorname{AR}(0)_{n}$ during the last quarter of 2008, which ranges from 2\% to 5\% for these three strategies. In Figure D.1 we explore the possibility that this spike in market-adjusted abnormal returns is due to the large market decline during the financial crisis. We thus plot the analogous time series of quarterly actual profits from these three strategies (Return $\left.(0)_{\mathrm{n}}\right)$, without subtracting the market return.

As expected, the mean one-day actual Return $(0)_{\mathrm{n}}$ in the last quarter of 2008 is smaller in Figure D. 1 than it is in Figure 5; it now ranges from 0\% to 3.5\% for portfolios I - III, when we do not short the (negative) market return during this quarter. On the other hand, a substantial spike in actual performance remains during this quarter in Figure D.1, especially for the DRIP stocks in portfolio III. Furthermore, the mean actual returns in Figure D.1 tend to be slightly higher than the analogous abnormal returns in Figure 5, for most quarters throughout the sample period, when we do not subtract the market return that is positive in most quarters. As a result, 
the average one-day actual return $\left(\operatorname{Returna}(0)_{\mathrm{n}}\right)$ across all quarters is similar to the average oneday abnormal return $\left(\operatorname{AR}(0)_{n}\right)$ presented in Figure 4, for all three strategies.

\section{VI.C.2. Quarterly Net Profits after Deducting Assumed Transaction Costs in the Bid-Ask Spread}

Our trading strategies allow the use of market-on-close orders, which would yield the mean close-to-close performance measures, Return $(0)_{\mathrm{n}}$ or $\operatorname{AR}(0)_{\mathrm{n}}$, documented in this study. This means that there is no need to consider the spread as a transaction cost. Still, in Figure D.2 we examine the analogous time series of quarterly net profits for each strategy, Return $(0)_{n}-\mathrm{TC}$, as if all purchases and sales took place at the daily close and incurred the closing spread.

Panels A - C of Figure D.2 track the actual and net profits from each strategy in turn. Each Panel reveals that, following decimalization in the second quarter of 2002, spreads decline so that this stream of net profits $\left(\operatorname{Return}(0)_{n}-\right.$ TC) tracks the actual profits $\left(\operatorname{Return}(0)_{\mathrm{n}}\right)$ closely, especially for portfolios I and II. Across all quarters since decimalization, the average one-day net returns are positive for all three strategies, even after deducting these assumed transaction costs $\left(\right.$ the mean $\left(\operatorname{Return}(0)_{\mathrm{n}}-\mathrm{TC}\right)=0.07 \%$ for portfolio I, $0.24 \%$ for portfolio II, and $0.30 \%$ for portfolio III). This evidence further establishes the economic significance of our findings.

\section{VI.C.3 Fama-French Regression on the Daily Stream of Mean Abnormal Profits, $A R(0)_{t}$}

Table D.1 provides further analysis of the risk and reward characteristics of our three trading strategies. This table presents the results from regressing the daily mean abnormal return from each strategy, $\operatorname{AR}(0)_{t}$, against the three daily Fama-French factors, as well as the daily momentum factor. The Fama-French daily alphas resulting from this analysis are extremely large and highly significant $(0.31 \%$ for portfolio I, $0.53 \%$ for portfolio II, and $0.99 \%$ for portfolio III). The magnitudes of these Fama-French alphas are similar to the average one-day performance measures, $\mathrm{AR}(0)_{\mathrm{n}}$, indicated across all quarters in Figures 4 and D.1. This evidence indicates 
that, even after controlling for common sources of risk, our proposed pay date trading strategies yield average risk-adjusted abnormal returns that range from 30 to 100 basis points per day.

\section{Summary and Conclusions}

This study analyzes the behavior of stock prices around the time that dividends are paid. We find a significant price run-up and reversal around the dividend pay date, consistent with the price pressure hypothesis. We focus on the role of DRIPs behind this pay date effect, using lists of firms with company-sponsored DRIPs since 1996. We find that this temporary inflation is significantly larger for DRIP stocks versus non-DRIP stocks. It is also exacerbated for finer subsets of DRIP stocks with a higher dividend yield that face limits to arbitrage. This evidence points to a substantial group of shareholders who routinely use their dividend income to buy more shares through DRIPs, resulting in temporary price pressure around the pay date.

These results are corroborated with further cross-sectional and time series analyses. For example, we show that the temporary inflation is larger for DRIP stocks that are subject to greater demand for shares through greater DRIP participation, and for DRIP firms with lower institutional ownership, or a higher dividend yield, spreads, or volatility. We also find that sophisticated investors act on this predictable price pressure by increasing their short sales activity on the days around the pay date. In addition, we show that several trading strategies designed to take advantage of this predictable price spike generate a reliable, economically significant stream of profits over time. This result does not change when we control for common risk factors in a Fama-French framework. We also show that time-variation in this stream of profits is positively related to market sentiment, as well as limits to arbitrage. These profits are surprisingly large and consistent over time given the nature of our proposed trading strategy, which simply exploits a predictable price increase around a recurring non-information event. 


\section{References}

Asquith, Paul, Parag Pathak, and Jay Ritter, 2005, Short Interest, Institutional Ownership, and Stock Returns, Journal of Financial Economics 78 (Issue 2), 243-276.

Baker, M., and J. Wurgler, 2004, A catering theory of dividends, Journal of Finance 59, 3, 1125 1164.

$61,4,1645-1680$.

,2006, Investor sentiment and the cross-section of stock returns, Journal of Finance ,2007, Investor sentiment in the stock market, Journal of Economic Perspectives 21,

$2,129-152$.

Beneish, M., and R. Whaley, 1996, AN anatomy of the 'S\&P Game': The effect of changing the rules, Journal of Finance 51, 1909-1930.

Berkman, Henk., Valentin Dimitrov, Prem C. Jain, Paul D. Koch, and Sheri Tice, 2009,Sell on the news: Differences of opinion, short-sales constraints, and returns around earnings announcements. Journal of Financial Economics 92, 376-399.

Berkman, Henk, Paul Koch, Laura Tuttle, and Ying Zhang, 2012 forthcoming, Paying attention: Overnight returns and the hidden cost of buying at the open, Journal of Financial and Quantitative Analysis.

Blouin, Jennifer, and C. Bryan Cloyd, 2005, Price pressure from dividend reinvestment activity: Evidence from closed end funds, Wharton School Working Paper.

Boehme, R., B. Danielsen, and S. Sorescu, 2006, Short sale constraints, differences of opinion, and overvaluation, Journal of Financial and Quantitative Analysis 41 (Issue 2), 455-477.

Boehmer, E., and E. Kelley, 2009, Institutional investors and the informational efficiency of stock prices, Review of Financial Studies 22, 3563-3594.

Carnival Corporation DRIP Document, Prospectus Supplement, “Automatic Dividend Reinvestment Plan of Carnival Corporation," Nov. 27, 2007, Carnival Corporation, Filed Pursuant to Rule 424(b)(3), Registration No. 333-106553, available at the following web site: https//www-us.computershare.com/Content/Download.asp?docID=\{4285723E-0BD1-4F6A9FA0-9EA34623625B $\} \& c c=U S \& l a n g=e n \& b h j s=1 \&$ fla $=1 \&$ theme $=$ cpu .

Chen, H., G. Noronha, and V. Singal, 2004, The price response to S\&P 500 Index additions and deletions: Evidence of asymmetry and a new explanation, Journal of Finance 59, 1901-1930.

Chiang, Kevin, George Frankfurter, and Arman Kosedag, 2005, Exploratory analyses of dividend reinvestment plans and some comparisons, International Review of Financial Analysis 14, 570-586. 
Chordia, T., R. Roll, and A. Subrahmanyam, 2008, Liquidity and market efficiency, Journal of Financial Economics 87, 249-268.

Chung, Kee, and Hao Zhang, 2013, A simple approximation of intraday spreads using daily data, forthcoming, Journal of Financial Markets.

Daniel, Kent, Mark Grinblatt, Sheridan Titman, and Russ Wermers, 1997, Measuring mutual fund performance with characteristic-based benchmarks. The Journal of finance 52, 1035-1058.

DeAngelo, Harry, Linda DeAngelo, and Douglas Skinner, 2009, Corporate payout policy, Foundations and Trends in Finance, 3, 2-3, 95-287.

Dhillon, Upinder, Dennis Lasser, and Gabriel Ramirez, 1992, Dividend reinvestment plans: An empirical analysis, Review of Quantitative Finance and Accounting 2, 205-213.

Diether, Karl, Christopher Malloy, and Anna Sherbina, 2002, Differences of Opinion and the Cross-Section of Stock Returns, Journal of Finance 57 (No. 5), 2113-2141.

Finnerty, John, 1989, New issue dividend reinvestment plans and the cost of capital, Journal of Business Research 18, 127-139.

Grullon, Gustavo, George Kanatas, and James P. Weston, 2004, Advertising, Breadth of Ownership, and Liquidity, Review of Financial Studies 17, 439-461.

Hartzmark, Samuel M., and David H. Solomon. 2013, The dividend month premium. Forthcoming, Journal of Financial Economics.

H.B. Fuller Company DRIP Document, 2011, A Dividend Reinvestment Plan for H.B. Fuller Company Common Stock, available at the following web site: https://www.shareowneronline.com/UserManagement/DisplayCompany.aspx.

Hansen, R., J. Pinkerton, and A. Keown, 1985, On dividend reinvestment plans: The adoption decision and stockholder wealth effects, Review of Business and Economic Research 20, 1-10.

Harris, L., and E. Gurel, 1986, Price and volume effects associated with changes in the S\&P 500 list: Evidence for the existence of price pressures, Journal of Finance 41, 815-829,

Holthausen, R., R. Leftwich, and D. Mayers, 1990, Large-block transactions, the speed of response, and temporary and permanent stock-price effects, Journal of Financial Economics 26, 71-95.

Jegadeesh, Narasimhan, and Sheridan Titman, 2001, "Profitability of momentum strategies: An evaluation of alternative explanations." The Journal of Finance 56, (No. 2): 699-720.

Kaul, A., V. Mehrotra, and R. Morck, 2000, Demand curves for stocks do slope down: New evidence from an Index Weights Adjustment, Journal of Finance 55, 893-912. 
Kumar, Alok, and Charles Lee, 2006, Retail investor sentiment and return comovements, Journal of Finance 61, 2451-2486.

McLean, R. David, and Jeffrey Pontiff, 2012, Does academic research destroy stock return predictability? Working paper, Boston College.

Larkin, Yelena, Mark T. Leary, and Roni Michaely, 2013, Do Investors Value Dividend Smoothing Stocks Differently? 2013, Penn State University Working Paper.

Mikkelson, W., and M. Partch, 1986, Valuation effects of security offerings and the issuance process, Journal of Financial Economics 15, 31-60.

Mitchell, Mark, T. Pulvino, and Erik Stafford, 2002, Limited arbitrage in equity markets, Journal of Finance 62, (No. 2, April), 551-584.

$31-63$. , 2004, Price pressure around mergers. Journal of Finance 59, (No. 1, February),

Nagel, Stefan, 2005, Short Sales, Institutional Investors and the cross-section of stock returns, Journal of Financial Economics 78 (Issue 2), 277-309.

Ogden, Joseph P., 1994, A dividend payment effect in stock returns, Financial Review 29, 3, 345-369.

Pettway, Richard, and R. Phil Malone, 1973, Automatic dividend reinvestment plans of nonfinancial corporations, Financial Management 2, 4, 11-18.

Peterson, Pamela P., D. R. Peterson, and N. H. Moore, 1987, The adoption of new-issue dividend reinvestment plans and shareholder wealth, Financial Review 22, 221-232.

Sadka Ronnie, and Anna Scherbina, 2007, Analyst disagreement, mispricing, and liquidity, Journal of Finance 62, 2367-2403.

Schleifer, A., 1986, Do demand curves for stock slope down? Journal of Finance 41, 579-590.

Schleifer, A., and R. Vishny, 1997, The limits of arbitrage," Journal of Finance 52, 35-55.

Scholes, Myron, 1972, The market for corporate securities: Substitution versus price pressure and the effects of information on share price, Journal of Business 45, 179-211.

Scholes, Myron, and Mark Wolfson, 1989, Decentralized investment banking: The case of discount dividend-reinvestment and stock-purchase plans, Journal of Financial Economics 23, 735. 
Schwert, G. William, 2003, Anomalies and market efficiency, Handbook of the Economics of Finance, Chapter 15, Ed., G. M. Constantinides, M. Harris, and R. Stulz, Elsevier Science B. V.

Stambaugh, Robert, Jianfeng Yu, and Yu Yuan, 2012, The short of it: Investor sentiment and anomalies," Journal of Financial Economics (104), 288-302.

Wermers, Russ, 2003, Is money really smart: New evidence on the relation between mutual fund flows, manager behavior, and performance persistance, University of Maryland Working paper.

Yadav, Vijay, 2010, The settlement period effect in stock returns around the dividend payment days, INSEAD Working paper. 
Figure 1. Mean Abnormal Returns and Trading Volume around Dividend Pay Dates, since 1975

This Figure plots mean abnormal returns and mean adjusted ranks for volume across all days in the event window, $(-5,+5)$, around dividend pay dates (on day 0 ). Abnormal returns are computed by subtracting the return on a benchmark portfolio matched to each stock by size and book-to-market ratio. The adjusted rank of volume is constructed by ranking the 21 days in the window $(-10,+10)$ by volume, and adjusting these ranks to range from -0.5 to +0.5 (i.e., Adjusted Rank $($ Volume $)=$ Rank $/ 21$ - 0.5). First, every quarter we sort stocks into quintiles by dividend yield. Second, within each quintile we compute the mean abnormal return and mean adjusted rank of volume for all days in the window. Third, for each quintile we compute the time series mean of these quarterly cross-sectional means for each day, $(-5,+5)$, across all quarters every decade. Results are plotted in Panels A - D for each decade since the 1970s. We plot the average results across quintiles $1-3$, since they are similar, along with the results for quintiles 4 and 5 separately. The $95 \%$ confidence interval is given in each Panel for the quintile with the highest dividend yield, since this quintile has the widest interval.

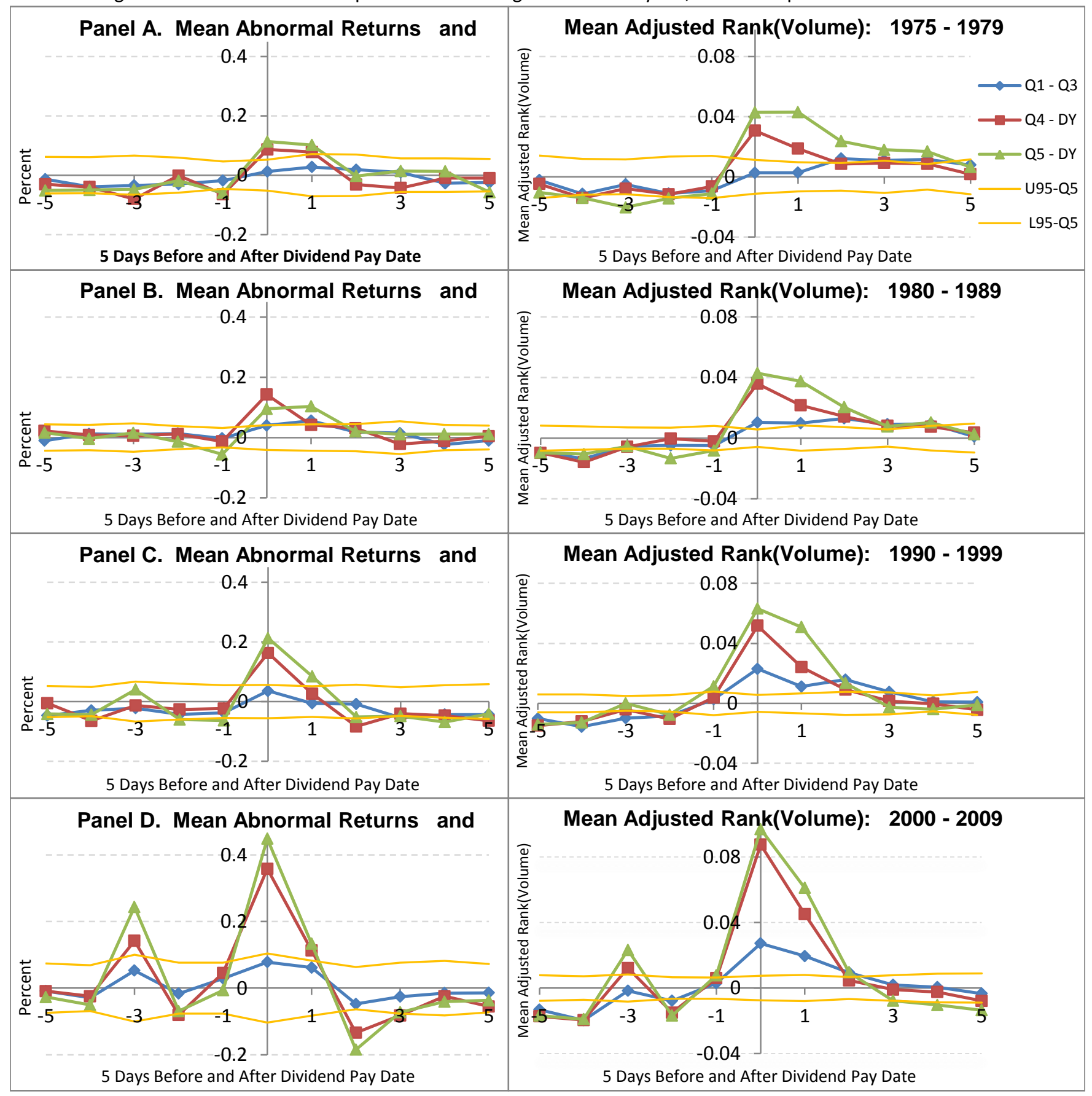




\section{Figure 2. Mean ARs and CARs for the DRIP or Non-DRIP Stocks in Two Portfolios}

This Figure plots the mean abnormal returns (ARs) and cumulative abnormal returns (CARs) across all 21 days in the event window, $(-10,+10)$, around dividend pay dates (on day 0$)$, for the DRIP stocks or non-DRIP stocks in two portfolios: all dividend-paying stocks, and a subset of high dividend yield stocks that are hard to arbitrage. We construct the second portfolio as follows. After independently sorting stocks each quarter by dividend yield, institutional ownershp, and the closing bid-ask spread as a percent of the mid-quote, we select:

the top $40 \%$ of all dividend-paying stocks each quarter by dividend yield, the bottom $40 \%$ of stocks by institutional ownership, and the top $40 \%$ of stocks by the spread.

First, daily abnormal returns are computed by subtracting the return on a benchmark portfolio matched to each stock by size and book-to-market ratio. Second, for the DRIP or non-DRIP stocks in the two portfolios, we compute the cross-sectional average ARs and CARs for all 21 days, during every quarter in the period, 1996 - 2009. Third, for each portfolio we compute the time series mean of these cross-sectional averages across all quarters. Panels $A$ and $B$ plot the resulting mean ARs and CARs, respectively, for the DRIP stocks in each portfolio. Panels $C$ and $D$ plot analogous results for the non-DRIP stocks in each portfolio. The $95 \%$ confidence band for the ARs in the second portfolio is provided in Panels A and C, since this portfolio has the widest band.

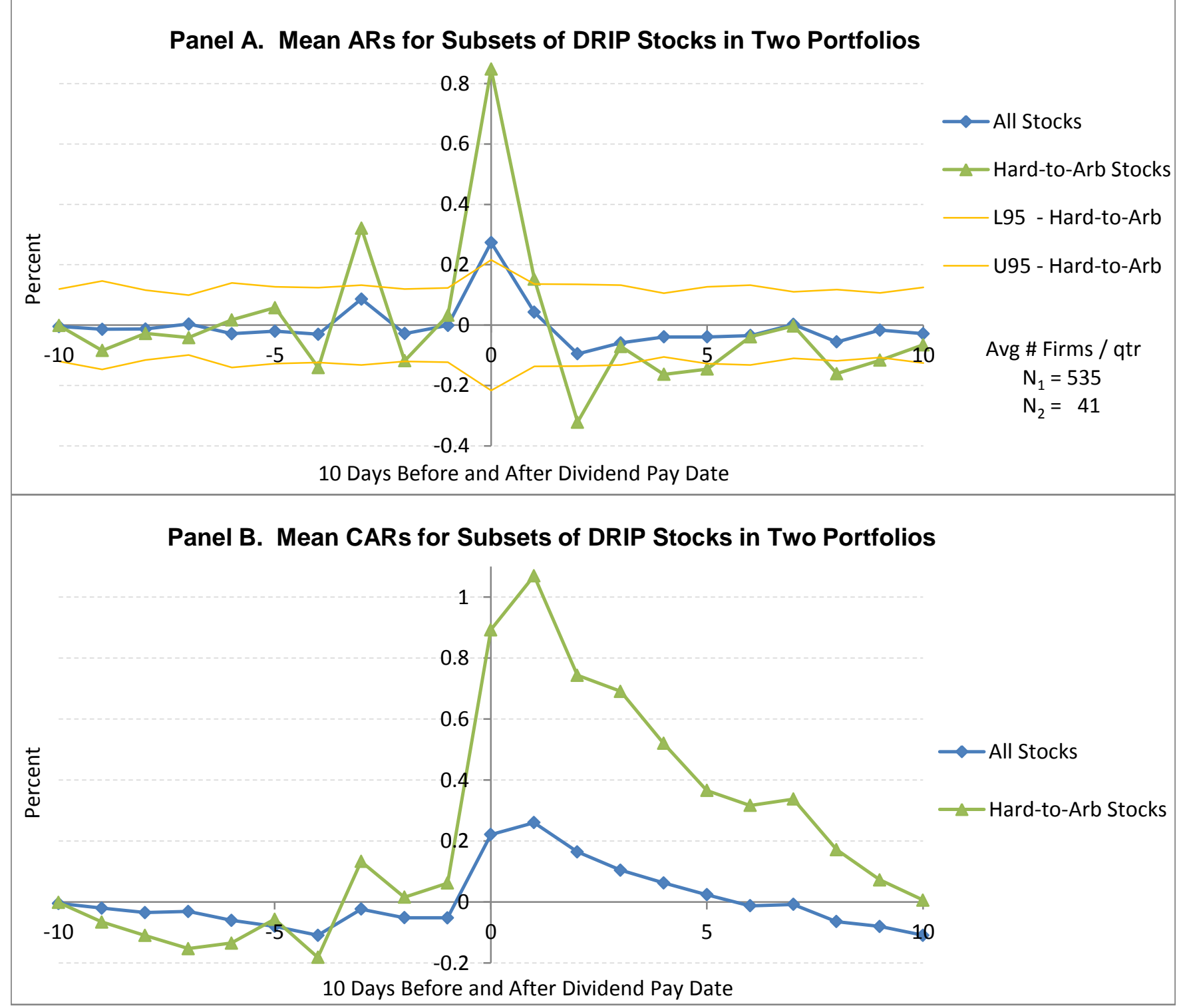


Figure 2, continued

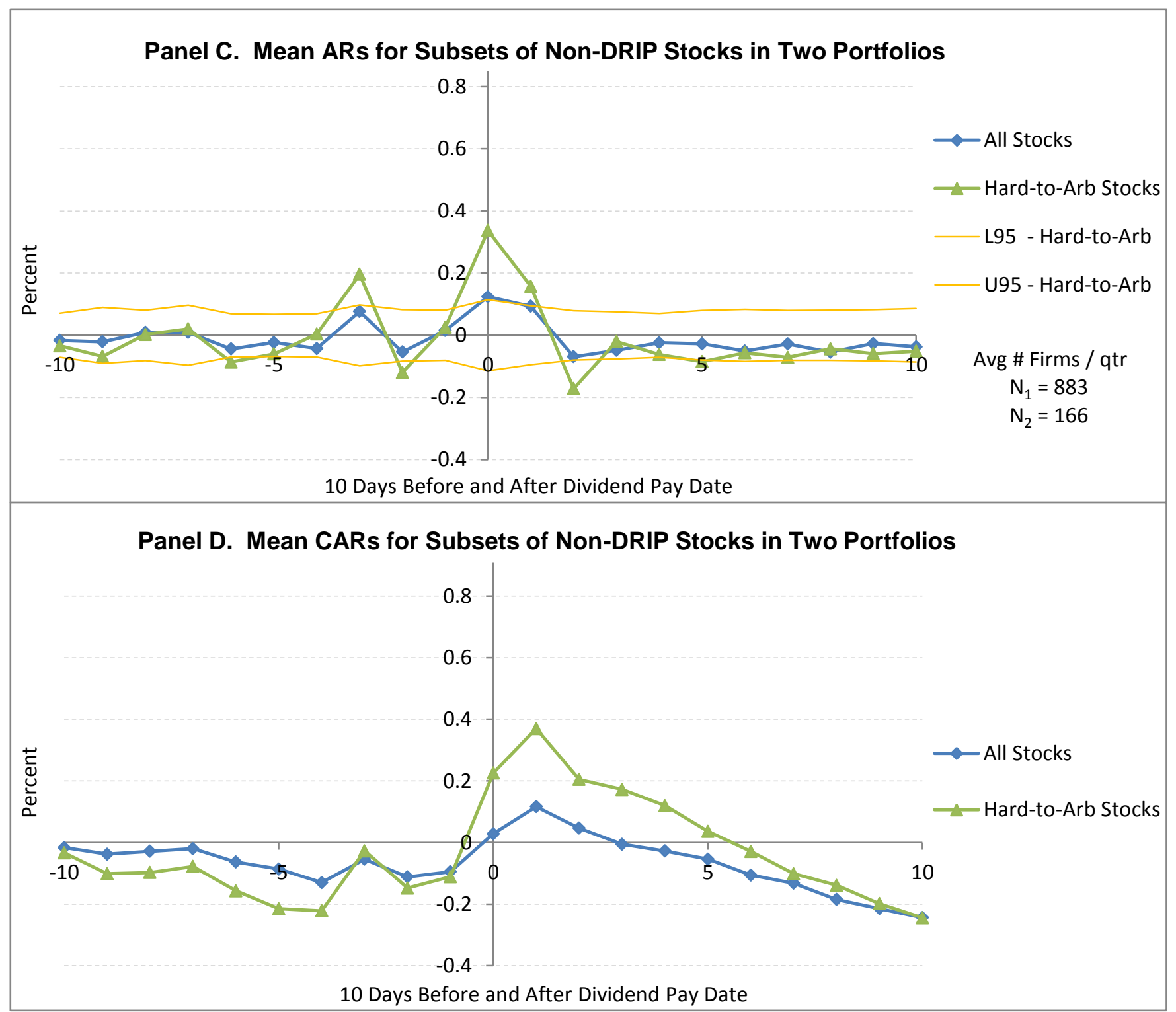




\section{Figure 3. Mean Abnormal Short Volume around the Dividend Pay Date}

This Figure plots the mean daily movements in abnormal short volume ( ASV $_{\text {itn }}$ ) for the subsets of DRIP stocks versus non-DRIP stocks in two portfolios each quarter: I (All stocks) and II (High_DY). There are too few firms in Portfolio III (Hard_Arb) with nonzero short volume to obtain reliable results. Abnormal short volume is defined as: $\mathrm{ASV}_{\mathrm{itn}}=(\mathrm{SV} / \mathrm{TV})_{\mathrm{itn}}-\operatorname{Normal}(\mathrm{SV} / \mathrm{TV})_{\mathrm{in}}$, where $(\mathrm{SV} / \mathrm{TV})_{\mathrm{itn}}=$ short volume as a proportion of total volume for stock $i$ on day $t$ during quarter $n$, and Normal(SV / TV $)_{\text {in }}$ is the mean (SV / TV) it over days $+11-+30$ after the dividend pay date (on day 0$)$. First, every quarter, for each day in the window, $(-10,+10)$, we compute the cross-sectional mean of ASV $_{\text {itn }}$ across the DRIP stocks or non-DRIP stocks in each portfolio. Second, we compute the time series mean of these cross-sectional means over the ten quarters for which we have short sales data, January 2005 - June 2007. The standard error of each time series mean is then used to construct the $95 \%$ confidence interval for the DRIP or Non-DRIP stocks in Portfolio II, for all 21 days in the event window.

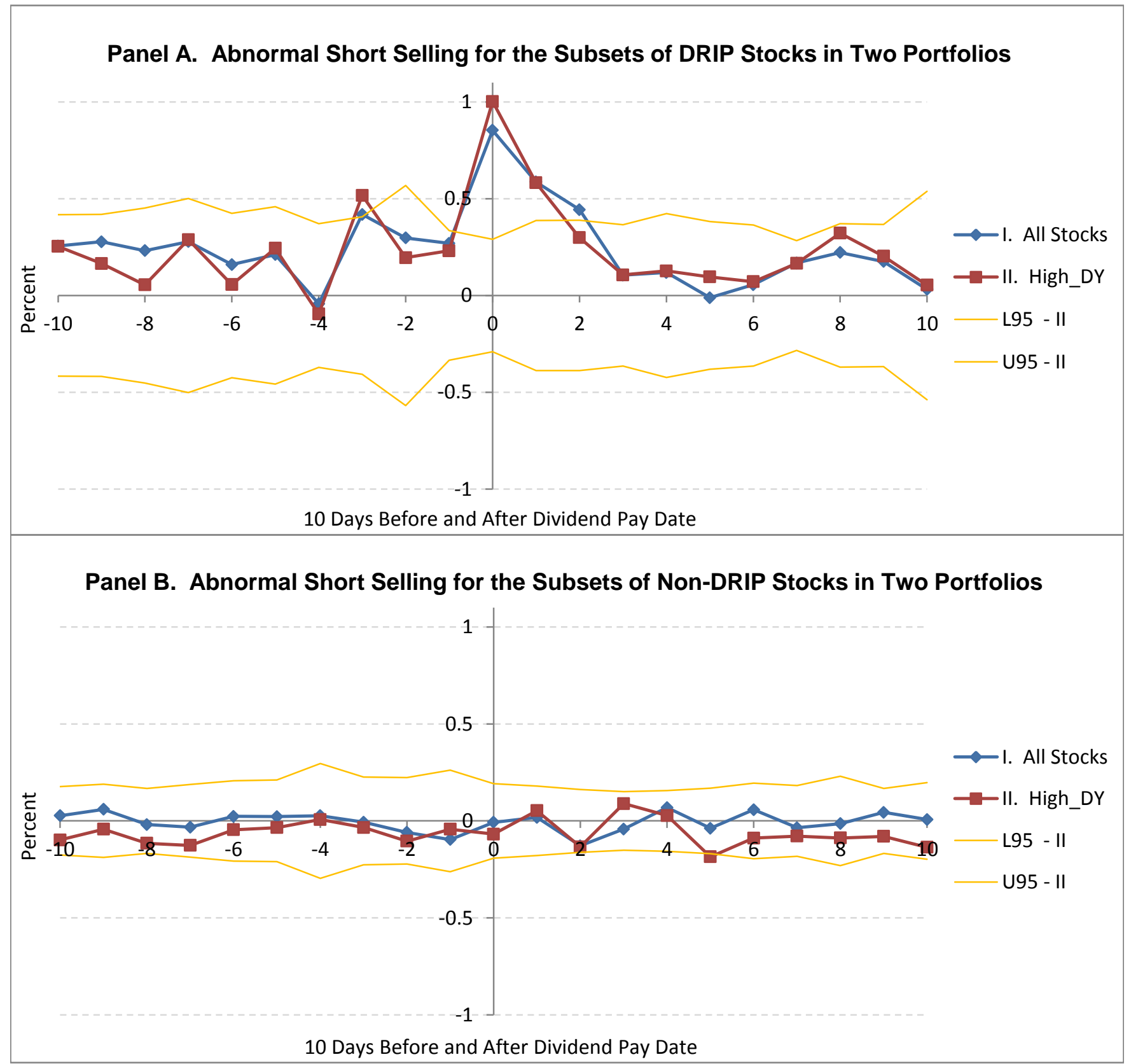




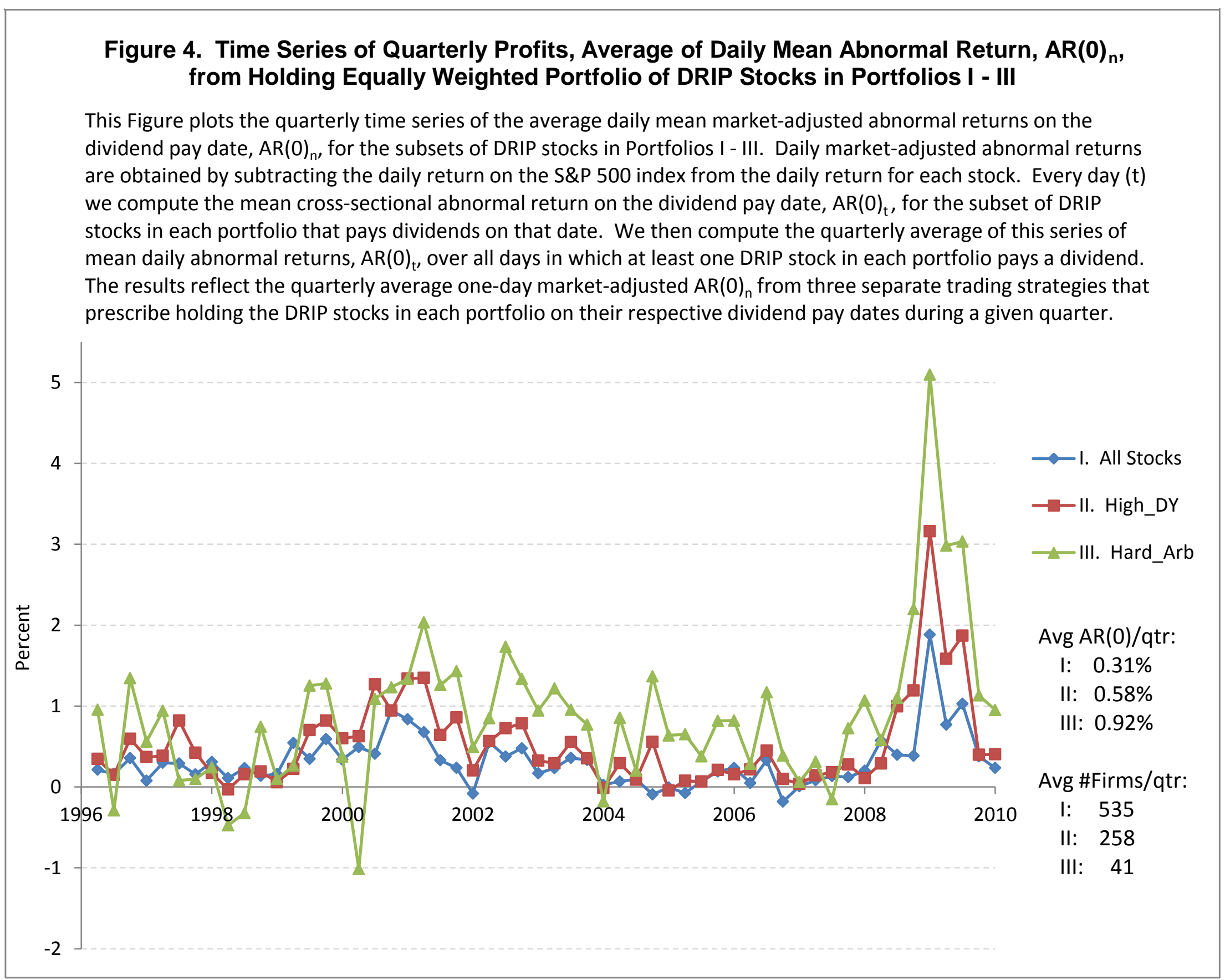


Table 1. Average Behavior of Stock Prices and Firm Characteristics for Three Portfolios of DRIP and Non-DRIP Firms

This table summarizes the descriptive statistics for the main variables over the sample period, $1996-2009$. $A R(-3), \operatorname{AR}(0), \operatorname{CAR}(0,+1), \mathrm{CAR}(+2,+10)$, and $\operatorname{CAR}(0,+10)$ are the percent (cumulative) abnormal returns over different periods around the dividend pay date (on day 0$)$. These abnormal returns are computed by subtracting the return on a benchmark portfolio matched to each stock by size and book-to-market ratio. "AR(ex-div)" is the analogous abnormal return on the ex-dividend date, while "AR(0) Mean Diff" is the mean of the difference between $A R(0)$ and $A R(e x$-div). Size in is daily market capitalization of the $i^{\text {th }}$ firm, averaged over days -10 through -6 prior to the $n^{\text {th }}$ quarterly pay date. Pct Inst $_{\text {in- } 1}$ is the percent of total shares outstanding held by financial institutions in the previous quarter $(n-1)$. CSHR ${ }_{\text {in }}$ is the number of shareholders, and Firm_Age ${ }_{\text {in }}$ is the number of years since the firm appeared on CRSP. The remaining variables appear as percentages, and are averaged over days -10 through -6 prior to the $\mathrm{n}^{\text {th }}$ quarterly pay date for the $i^{\text {th }}$ firm: Div_Yield ${ }_{i n}$ is the quarterly dividend amount divided by the daily closing price; Spread $_{\text {in }}$ is the daily closing spread divided by the share price; and $\mathrm{Log}_{-} \mathrm{HiLO}_{\text {in }}$ is the natural log of the ratio of the daily high to the daily low. Panels A - $\mathrm{C}$ give the results for three different portfolios of stocks selected each quarter, with and without DRIPs. Panel A provides the results for Portfolio I (All dividend-paying stocks), while Panels $B$ and $C$ present the results for Portfolio II (High_DY) and Portfolio III (Hard_Arb), which are described in the text. In every Panel we provide five sets of results for: (i) all stocks in that portfolio, (ii) DRIP stocks, (iii) Non-DRIP stocks, (iv) the difference of means across DRIP and Non-DRIP stocks, and (v) the analogous results for a subset of matched pairs within every portfolio. First, every quarter we compute the cross-sectional average for each variable. Second, we compute the time series mean of these averages across all quarters in the sample, and use the standard error of this mean to construct the t-statistics.

\begin{tabular}{|c|c|c|c|c|c|c|c|c|c|c|}
\hline Panel A. & \multicolumn{2}{|c|}{$\begin{array}{cc}\text { Portfolio I. } & \text { All Stocks } \\
\begin{array}{cc}(1) & (2) \\
\text { mean } & \text { (t-stat) } \\
\end{array}\end{array}$} & $\begin{array}{l}\text { I. All D } \\
(3) \\
\text { mean }\end{array}$ & $\begin{array}{l}\text { Stocks } \\
\qquad \begin{array}{c}(4) \\
\text { (t-stat) }\end{array}\end{array}$ & $\begin{array}{l}\text { I. All Nor } \\
\begin{array}{c}(5) \\
\text { mean }\end{array}\end{array}$ & $\begin{array}{l}\text { IP Stocks } \\
\qquad 6) \\
\text { (t-stat) }\end{array}$ & $\begin{array}{l}\text { I. Diff of Means } \\
\begin{array}{l}(3)-(5) \\
(7)\end{array} \\
\text { DRIP - Non-DRIP }\end{array}$ & $\begin{array}{c}(8) \\
\text { DRIP }\end{array}$ & $\begin{array}{l}\text { Matched P } \\
\text { (9) } \\
\text { Non-DRIP }\end{array}$ & $\begin{array}{l}\text { (10) } \\
\text { Mean Diff }\end{array}$ \\
\hline \# firms per qtr & 1,418 & 59.0 & 535 & 37.5 & 883 & 47.5 & $-348 * * *$ & 286 & 286 & 0 \\
\hline$A R(-3)_{\text {in }} \%$ & .08 & 4.2 & .09 & 4.8 & .08 & 3.4 & .01 & .09 & .07 & .02 \\
\hline $\operatorname{AR}(0)_{\text {in }} \%$ & .19 & 8.4 & .27 & 9.1 & .12 & 5.3 & $.15^{* * *}$ & .31 & .12 & $.19^{* * *}$ \\
\hline $\operatorname{CAR}(0,+1)_{\text {in }} \%$ & .27 & 6.4 & .32 & 6.6 & .22 & 5.1 & .10 & .37 & .20 & $.16^{* * *}$ \\
\hline $\operatorname{CAR}(+2,+10)_{\text {in }} \%$ & -.36 & -3.5 & -.37 & -3.9 & -.35 & -3.2 & -.02 & -.35 & -.27 & -.08 \\
\hline $\operatorname{CAR}(0,+10)_{\text {in }} \%$ & -.09 & -0.7 & -.05 & -0.4 & -.14 & -1.0 & .09 & .01 & -.07 & .08 \\
\hline$A R(e x-d i v)_{\text {in }} \%$ & .26 & 12.3 & .17 & 8.3 & .31 & 12.7 & $-.15^{* * *}$ & .21 & .25 & -.03 \\
\hline AR(0) Mean Diff & -.07 & -3.2 & .11 & 4.2 & -.19 & -7.1 & $.29^{* * *}$ & .10 & -.13 & $.22^{* * *}$ \\
\hline Size $_{\text {in }}$ (millions) & $\$ 5,579$ & 29.3 & $\$ 11,660$ & 24.2 & $\$ 2,039$ & 21.8 & $\$ 9,620 * * *$ & $\$ 3,433$ & $\$ 3,581$ & $-\$ 148 * * *$ \\
\hline Div_Yield $_{\text {in }} \%$ & .65 & 45.2 & .70 & 49.8 & .62 & 40.6 & $.07^{* * *}$ & .61 & .61 & .00 \\
\hline Pct_Inst ${ }_{i n-1} \%$ & 48.3 & 43.8 & 56.72 & 52.7 & 43.49 & 35.0 & $13.23^{* * *}$ & 53.86 & 53.16 & $.71^{* * *}$ \\
\hline Spread $_{\text {in }} \%$ & 1.48 & 12.9 & .92 & 10.5 & 1.84 & 13.3 & $-.92 * * *$ & 1.11 & 1.12 & -.01 \\
\hline $\log _{-} \mathrm{HiLo}_{\text {in }} \%$ & 3.01 & 19.7 & 2.76 & 17.8 & 3.17 & 20.2 & $-.41 *$ & 2.83 & 3.03 & $-.20^{* * *}$ \\
\hline $\mathrm{CSHR}_{\mathrm{in}}{ }^{\mathrm{a}} \%$ & 4,316 & 55.1 & 13,036 & 62.3 & 1,625 & 59.8 & $11,411 * * *$ & 6,863 & 2,619 & $2,975 * * *$ \\
\hline Firm_Age $_{\text {in }} \%$ & 23.46 & 114.3 & 33.83 & 103.1 & 17.36 & 83.5 & $16.47^{* * *}$ & 28.70 & 20.01 & $8.68^{* * *}$ \\
\hline
\end{tabular}

${ }^{*}$ indicates significance at the .10 level; ${ }^{* *}$ at the .05 level; and ${ }^{* * *}$ at the .01 level, for the mean difference t-test in the last column.

${ }^{a}$ CSHR is extremely skewed. Thus we present the time series mean of the quarterly cross-sectional medians for this variable. 
Table 1, continued

\begin{tabular}{|c|c|c|c|c|c|c|c|c|c|c|}
\hline Panel B. & \multicolumn{2}{|c|}{$\begin{array}{cc}\begin{array}{c}\text { Portfolio II. High_DY } \\
\text { mean }\end{array} & \text { (t-stat) } \\
\end{array}$} & \multicolumn{2}{|c|}{ DRIP Stocks in II. } & \multicolumn{2}{|c|}{ Non-DRIP Stocks in II. } & $\begin{array}{l}\text { II. Diff of Means } \\
\text { DRIP - Non-DRIP }\end{array}$ & \multicolumn{3}{|c|}{ II. Matched Pairs } \\
\hline \# firms per qtr & 567 & 59.0 & 258 & 30.3 & 310 & 52.3 & $-52 * * *$ & 81 & 81 & 0 \\
\hline$A R(-3)_{\text {in }} \%$ & .15 & 5.7 & .14 & 5.4 & .17 & 4.6 & -.02 & .20 & .18 & .02 \\
\hline $\mathrm{AR}(0)_{\text {in }} \%$ & .37 & 8.8 & .47 & 8.5 & .26 & 6.5 & $.20 * * *$ & .56 & .23 & $.34 * * *$ \\
\hline $\operatorname{CAR}(0,+1)_{\text {in }} \%$ & .49 & 7.6 & .54 & 6.8 & .40 & 6.6 & .14 & .68 & .32 & $.36^{* * *}$ \\
\hline $\operatorname{CAR}(+2,+10)_{\text {in }} \%$ & -.53 & -3.9 & -.55 & -4.3 & -.53 & -3.5 & -.02 & -.57 & -.40 & -.18 \\
\hline $\operatorname{CAR}(0,+10)_{\text {in }} \%$ & -.05 & -0.3 & -.01 & 0.0 & -.13 & -0.7 & .12 & .11 & -.08 & .18 \\
\hline ex-div $A R(0)_{\text {in }} \%$ & .40 & 12.2 & .21 & 6.9 & .55 & 12.7 & $-.33 * * *$ & .34 & .44 & $-.11 * *$ \\
\hline AR(0) Mean Diff & -.02 & -0.5 & .25 & 5.5 & -.27 & -5.3 & $.52^{* * *}$ & .21 & -.19 & $.40^{* * *}$ \\
\hline Size $_{\text {in }}$ (millions) & $\$ 4,333$ & 16.5 & $\$ 8,704$ & 14.0 & $\$ 1,090$ & 11.9 & $\$ 7,614 * * *$ & $\$ 1,577$ & $\$ 1,566$ & $\$ 11$ \\
\hline Div_Yield $_{\text {in }} \%$ & 1.09 & 43.1 & 1.04 & 46.4 & 1.14 & 35.9 & $-.10 * * *$ & 1.00 & 1.06 & $-.06 * * *$ \\
\hline Pct_Inst $_{\text {in-1 }} \%$ & 38.15 & 40.4 & 48.78 & 48.5 & 29.99 & 28.2 & $18.8^{* * *}$ & 39.81 & 39.75 & .06 \\
\hline Spread $_{\text {in }} \%$ & 1.79 & 14.8 & 1.04 & 11.0 & 2.44 & 15.0 & $-1.40 * * *$ & 1.46 & 1.46 & .00 \\
\hline Log_HiLo $_{\text {in }} \%$ & 2.92 & 18.0 & 2.62 & 16.2 & 3.19 & 18.7 & $-.57 * *$ & 2.72 & 2.91 & $-.20 * * *$ \\
\hline $\mathrm{CSHR}_{\mathrm{in}}{ }^{\mathrm{a}} \%$ & 6,140 & 46.6 & 16,956 & 40.6 & 1,348 & 32.9 & $15,608 * * *$ & 7,535 & 2,617 & $3,618 * * *$ \\
\hline Firm_Age $_{\text {in }} \%$ & 24.59 & 112.8 & 34.75 & 96.2 & 16.48 & 80.4 & $18.27^{* * *}$ & 27.51 & 18.63 & $8.87^{* * *}$ \\
\hline Panel C. & $\begin{array}{c}\text { Portfolio } \\
\text { mean }\end{array}$ & $\begin{array}{c}\text { Hard_Arb } \\
\text { (t-stat) }\end{array}$ & $\begin{array}{l}\text { DRIP S } \\
\text { mean }\end{array}$ & $\begin{array}{l}\text { s in III. } \\
\text { (t-stat) }\end{array}$ & $\begin{array}{c}\text { Non-DRI } \\
\text { mean }\end{array}$ & $\begin{array}{c}\text { cks in III. } \\
\text { (t-stat) }\end{array}$ & $\begin{array}{l}\text { III. Diff of Means } \\
\text { DRIP - Non-DRIP }\end{array}$ & DRIP & $\begin{array}{l}\text { Matched } \\
\text { Non-DRIP } \\
\end{array}$ & $\begin{array}{l}\text { rs } \\
\text { Mean Diff }\end{array}$ \\
\hline \# firms per qtr & 207 & 49.3 & 41 & 14.5 & 166 & 33.7 & $-124 * * *$ & 19 & 19 & 0 \\
\hline$A R(-3)_{\text {in }} \%$ & .22 & 5.0 & .32 & 4.9 & .20 & 4.3 & .12 & .38 & .19 & .19 \\
\hline $\operatorname{AR}(0)_{\text {in }} \%$ & .48 & 7.2 & .85 & 7.6 & .34 & 5.9 & $.51^{* * *}$ & .94 & .28 & $.66^{* * *}$ \\
\hline $\operatorname{CAR}(0,+1)_{\text {in }} \%$ & .67 & 7.1 & 1.02 & 7.1 & .51 & 5.9 & $.51 * * *$ & 1.02 & .54 & $.48 * *$ \\
\hline $\operatorname{CAR}(+2,+10)_{\text {in }} \%$ & -.67 & -3.4 & -1.11 & -4.6 & -.56 & -3.0 & $-.56 *$ & -1.37 & -.22 & $-1.14^{* * *}$ \\
\hline $\operatorname{CAR}(0,+10)_{\text {in }} \%$ & .00 & 0.0 & -.11 & -0.3 & -.06 & -0.2 & -.05 & -.38 & .32 & -.68 \\
\hline ex-div $A R(0)_{\text {in }} \%$ & .67 & 13.8 & .59 & 7.9 & .67 & 13.0 & -.08 & .74 & .70 & .01 \\
\hline$A R(0)$ Mean Diff & -.17 & -2.6 & .26 & 2.6 & -.30 & -4.7 & $.56^{* * *}$ & .20 & -.34 & $.50^{* *}$ \\
\hline Size $_{\text {in }}$ (millions) & $\$ 164$ & 23.0 & $\$ 367$ & 10.9 & $\$ 121$ & 20.9 & $\$ 246 * * *$ & $\$ 145$ & $\$ 161$ & $-\$ 15 * *$ \\
\hline Div_Yield ${ }_{\text {in }} \%$ & 1.13 & 40.2 & 1.09 & 38.1 & 1.14 & 36.2 & -.05 & 1.02 & 1.11 & $-.09 *$ \\
\hline Pct_Inst ${ }_{\text {in-1 }} \%$ & 14.09 & 25.6 & 18.12 & 28.9 & 13.24 & 24.2 & $4.88^{* * *}$ & 15.46 & 15.86 & -.40 \\
\hline Spread $_{\text {in }} \%$ & 3.36 & 15.9 & 2.46 & 13.1 & 3.61 & 15.7 & $-1.14^{* * *}$ & 2.73 & 2.62 & $.11^{* *}$ \\
\hline Log_HiLo in $\%$ & 3.32 & 21.1 & 2.94 & 19.1 & 3.45 & 20.5 & $-.51 * *$ & 2.86 & 2.90 & -.04 \\
\hline $\mathrm{CSHR}_{\mathrm{in}}{ }^{\mathrm{a}} \%$ & 1,134 & 41.9 & 3,109 & 16.0 & 830 & 46.0 & $2,279 * * *$ & 2,113 & 1,433 & $704 * *$ \\
\hline Firm_Age $_{\text {in }} \%$ & 14.40 & 59.7 & 19.86 & 47.5 & 13.37 & 46.0 & $6.49 * * *$ & 17.91 & 12.89 & $5.02 * * *$ \\
\hline
\end{tabular}




\section{Table 2. Correlations across Return Measures Taken over Different Time Frames around the Pay Date}

This Table provides correlations across the return measures taken over five different time frames around the quarterly dividend pay date: $A R(-3), A R(0)$, $\mathrm{CAR}(0,+1), \mathrm{CAR}(+2,+5)$, and $\mathrm{CAR}(+2,+10)$. We compute these correlations across all stocks, DRIP stocks, and non-DRIP stocks within three portfolios selected each quarter. Panel A presents the results for Portfolio I (All dividend-paying stocks), while Panels B and C provide the results for Portfolio II (High_DY) and Portfolio III (Hard_Arb.), which are described in the text. The mean correlations are calculated in two stages. First we compute every pairwise cross-sectional Pearson or Spearman correlation across the dividend events for every portfolio each quarter. Second, we compute the time series mean for every pairwise cross-sectional correlation across all quarters in the sample. The standard deviation of every time series mean correlation is then used to construct the t-test of the null hypothesis that every mean correlation equals zero. The mean Pearson correlations are presented above the diagonal, and the mean Spearman correlations appear below the diagonal. Correlations in BOLD are significant at the .05 level.

\begin{tabular}{|c|c|c|c|c|c|c|c|c|c|c|c|c|c|c|c|}
\hline \multirow[t]{2}{*}{ Panel A. } & \multicolumn{5}{|c|}{ Portfolio I. All Dividend-Paying Stocks } & \multicolumn{5}{|c|}{ I. All DRIP Stocks } & \multicolumn{5}{|c|}{ I. All Non-DRIP Stocks } \\
\hline & $A R(-3)$ & $A R(0)$ & $\operatorname{CAR}(0,1)$ & $\operatorname{CAR}(2,5)$ & $\operatorname{CAR}(2,10)$ & $A R(-3)$ & $A R(0)$ & $\operatorname{CAR}(0,1)$ & $\operatorname{CAR}(2,5)$ & $\operatorname{CAR}(2,10)$ & $A R(-3)$ & $A R(0)$ & $\operatorname{CAR}(0,1)$ & $\operatorname{CAR}(2,5)$ & $\operatorname{CAR}(2,10)$ \\
\hline $\mathrm{AR}(-3)$ & 1.00 & .00 & .01 & -.01 & -.01 & 1.00 & .01 & .01 & -.01 & .00 & 1.00 & .00 & .00 & -.01 & -.01 \\
\hline $\mathrm{AR}(0)$ & .01 & 1.00 & .68 & -.01 & .00 & .00 & 1.00 & .69 & -.01 & .00 & .00 & 1.00 & .67 & -.01 & .00 \\
\hline $\operatorname{CAR}(0,1)$ & .01 & .65 & 1.00 & -.06 & -.03 & .00 & .67 & 1.00 & -.04 & -.03 & .01 & .64 & 1.00 & -.07 & -.04 \\
\hline $\operatorname{CAR}(2,5)$ & -.01 & -.01 & -.05 & 1.00 & .64 & -.01 & -.02 & -.04 & 1.00 & .64 & .00 & -.01 & -.06 & 1.00 & .64 \\
\hline $\operatorname{CAR}(2,10)$ & .00 & -.01 & -.04 & .62 & 1.00 & .00 & -.01 & -.03 & .62 & 1.00 & -.01 & -.01 & -.05 & .62 & 1.00 \\
\hline \multirow[t]{2}{*}{ Panel B. } & \multicolumn{5}{|c|}{ Portfolio II. High_DY } & \multicolumn{5}{|c|}{ DRIP Stocks in Portfolio II } & \multicolumn{5}{|c|}{ Non-DRIP Stocks in Portfolio II } \\
\hline & $\mathrm{AR}(-3)$ & $A R(0)$ & $\operatorname{CAR}(0,1)$ & $\operatorname{CAR}(2,5)$ & $\operatorname{CAR}(2,10)$ & $A R(-3)$ & $A R(0)$ & $\operatorname{CAR}(0,1)$ & $\operatorname{CAR}(2,5)$ & $\operatorname{CAR}(2,10)$ & $A R(-3)$ & $A R(0)$ & $\operatorname{CAR}(0,1)$ & CAR(2,5) & $\operatorname{CAR}(2,10)$ \\
\hline$A R(-3)$ & 1.00 & .01 & .01 & -.03 & -.02 & 1.00 & .03 & .03 & .00 & .01 & 1.00 & .00 & .00 & -.03 & -.03 \\
\hline$A R(0)$ & .01 & 1.00 & .67 & -.03 & -.01 & .01 & 1.00 & .71 & -.01 & .00 & .01 & 1.00 & .65 & -.03 & -.01 \\
\hline $\operatorname{CAR}(0,1)$ & .01 & .65 & 1.00 & -.08 & -.05 & .01 & .68 & 1.00 & -.04 & -.04 & .02 & .62 & 1.00 & -.11 & -.06 \\
\hline $\operatorname{CAR}(2,5)$ & -.02 & -.01 & -.07 & 1.00 & .64 & .00 & -.02 & -.04 & 1.00 & .65 & -.02 & -.01 & -.09 & 1.00 & .63 \\
\hline $\operatorname{CAR}(2,10)$ & -.01 & -.02 & -.06 & .63 & 1.00 & .00 & -.02 & -.05 & .63 & 1.00 & -.02 & -.01 & -.07 & .62 & 1.00 \\
\hline \multirow[t]{2}{*}{ Panel C. } & \multicolumn{5}{|c|}{ Portfolio III. Hard_Arb } & \multicolumn{5}{|c|}{ DRIP Stocks in Portfolio III } & \multicolumn{5}{|c|}{ Non-DRIP Stocks in Portfolio III } \\
\hline & $A R(-3)$ & $\mathrm{AR}(0)$ & $\operatorname{CAR}(0,1)$ & $\mathrm{CAR}(2,5)$ & $\operatorname{CAR}(2,10)$ & $A R(-3)$ & $A R(0)$ & $\operatorname{CAR}(0,1)$ & $\operatorname{CAR}(2,5)$ & $\operatorname{CAR}(2,10)$ & $\mathrm{AR}(-3)$ & $\mathrm{AR}(0)$ & $\operatorname{CAR}(0,1)$ & $\operatorname{CAR}(2,5)$ & $\operatorname{CAR}(2,10)$ \\
\hline $\mathrm{AR}(-3)$ & 1.00 & .01 & .01 & -.02 & -.02 & 1.00 & .01 & .01 & .05 & .02 & 1.00 & .00 & .01 & -.03 & -.03 \\
\hline$A R(0)$ & .02 & 1.00 & .64 & -.05 & -.03 & -.01 & 1.00 & .67 & -.07 & -.06 & .02 & 1.00 & .62 & -.04 & -.02 \\
\hline $\operatorname{CAR}(0,1)$ & .02 & .61 & 1.00 & -.15 & -.10 & .01 & .64 & 1.00 & -.15 & -.14 & .02 & .59 & 1.00 & -.15 & -.09 \\
\hline $\operatorname{CAR}(2,5)$ & -.02 & -.03 & -.14 & 1.00 & .64 & .04 & -.07 & -.13 & 1.00 & .67 & -.03 & -.02 & -.14 & 1.00 & .63 \\
\hline $\operatorname{CAR}(2,10)$ & -.02 & -.03 & -.11 & .63 & 1.00 & .04 & -.06 & -.13 & .65 & 1.00 & -.03 & -.02 & -.10 & .63 & 1.00 \\
\hline
\end{tabular}




\section{Table 3. The Number of Shareholders, DRIP Participation, and Abnormal Returns Around the Dividend Pay Date}

This table presents results from estimating two regression models. The first model analyzes the relation between the number of shareholders for a firm (CSHR) and certain firm characteristics, and it is used to generate our proxy for DRIP participation. The second model describes how the abnormal return around the dividend pay date $(\operatorname{AR}(0)$ or $\operatorname{CAR}(0,1))$ is influenced by our proxy for DRIP participation and firm characteristics, as follows:

$$
\text { Log_CSHR }_{\text {in }}=\alpha_{0}+\alpha_{1} \text { Firm_Age }_{\text {in }}+\alpha_{2} \text { Log_Size }_{\text {in }}+\alpha_{3} \text { Div_Yield }_{\text {in }}+\alpha_{4} \text { Pct_INST }_{\text {in }}+\alpha_{5} \text { Spread }_{\text {in }}+\alpha_{6} \text { Log_Hilo }_{\text {in }}+\varepsilon_{\text {in }} \text {, }
$$

$\left(\operatorname{AR}(0)_{\text {in }}\right.$ or CAR $\left.(0,1)_{\text {in }}\right)=\beta_{0}+\beta_{1}$ DRIP_Part $_{\text {in }}+\beta_{2}$ Log_Size $_{\text {in }}+\beta_{3}$ Div_Yield $_{\text {in }}+\beta_{4}$ Pct_INST $_{\text {in }}+\beta_{5}$ Spread $_{\text {in }}+\beta_{6}$ Log_Hilo $_{\text {in }}+v_{\text {in }}$.

All variables are defined in Table 1. We apply the Fama-MacBeth approach to estimate Equation (1) every quarter, for the subsets of all DRIP stocks or all non-DRIP stocks, separately. The Newey-West robust standard error of each time series mean coefficient (with $L=1)$ is used to construct each t-statistic. The actual values and fitted values from Equation (1) are then used to construct our proxy for DRIP participation, as follows: DRIP_Part in = $\log _{2} \mathrm{CSHR}_{\text {in }} /$ Fitted Value in. This proxy captures the actual number of shareholders for each firm (Log_CSHR ), relative to the predicted value of $\log _{-} \mathrm{CSHR}_{\text {in }}$ each quarter, given the fitted model from Equation (1). We then estimate the Panel in Equation (2) with standard errors clustered on the firm and the quarter of the dividend payment. We provide three sets of results: one set for Equation (1), and two sets for Equation (2) applied to AR(0) in and $\operatorname{CAR}(0,1)_{\text {in }}$, respectively. Each set of results appears in three columns that contain the estimates for: (1) all firms with DRIPs, (2) all firms without DRIPs, and (3) the differences across firms with and without DRIPs. At the bottom of column (3) in each set of results, we present the Chow test of the joint hypothesis that all coefficients in Equation (1) or (2) are identical across the subsamples of DRIP stocks and non-DRIP stocks, respectively, along with the total number $(\mathrm{N})$ of quarterly dividend events for both DRIP and non-DRIP stocks used in the analysis.

\begin{tabular}{|c|c|c|c|c|c|c|c|c|c|c|}
\hline \multirow[t]{2}{*}{ Column: } & \multicolumn{3}{|c|}{$\begin{array}{l}\text { Dep Var for }(1)=\text { Log_CSHR } \\
\begin{array}{lll}\text { (1) } & \text { (2) } & \text { (3) }\end{array}\end{array}$} & \multirow[t]{2}{*}{ Column: } & \multicolumn{3}{|c|}{$\begin{array}{l}\text { Dep Var for (2) }=\mathbf{A R}(0) \\
(1)\end{array}$} & \multicolumn{3}{|c|}{$\begin{array}{l}\text { Dep Var for }(2)=\operatorname{CAR}(0,1) \\
(1)\end{array}$} \\
\hline & DRIP & Non-DRIP & $(1)-(2)$ & & DRIP & Non-DRIP & $(1)-(2)$ & DRIP & Non-DRIP & $(1)-(2)$ \\
\hline${ }^{F i r m} \_$Age $_{\text {in }}$ & $\begin{array}{l}.005 \\
14.6^{* * *}\end{array}$ & $\begin{array}{l}.015 \\
21.6 * * *\end{array}$ & $\begin{array}{l}-.010 \\
-12.5 * * *\end{array}$ & DRIP_Part $_{\text {in }}$ & $\begin{array}{l}.43 \\
2.5^{* *}\end{array}$ & $\begin{array}{l}.00 \\
0.0\end{array}$ & $\begin{array}{l}.43 \\
2.3 * *\end{array}$ & $\begin{array}{l}.48 \\
2.1 * *\end{array}$ & $\begin{array}{l}.05 \\
0.4\end{array}$ & $\begin{array}{l}.43 \\
1.7^{*}\end{array}$ \\
\hline Log_Size $_{\text {in }}$ & $\begin{array}{l}.72 \\
99.8^{* * *}\end{array}$ & $\begin{array}{l}.53 \\
70.8^{* * *}\end{array}$ & $\begin{array}{c}.19 \\
23.2^{* * *}\end{array}$ & Log_Size $_{\text {in }}$ & $\begin{array}{r}-.005 \\
-0.4\end{array}$ & $\begin{array}{r}.004 \\
0.3\end{array}$ & $\begin{array}{r}-.009 \\
-0.4\end{array}$ & $\begin{array}{r}-.025 \\
-1.2\end{array}$ & $\begin{array}{r}-.007 \\
-0.4\end{array}$ & $\begin{array}{r}-.018 \\
-0.5\end{array}$ \\
\hline Div_Yield $_{\text {in }}$ & $\begin{array}{l}80.59 \\
21.2 * * *\end{array}$ & $\begin{array}{l}14.37 \\
5.9^{* * *}\end{array}$ & $\begin{array}{l}66.22 \\
14.7^{* * *}\end{array}$ & Div_Yield in & $\begin{aligned} & 30.42 \\
& 1.8 *\end{aligned}$ & $\begin{array}{l}8.41 \\
2.9 * * *\end{array}$ & $\begin{array}{r}22.01 \\
1.3\end{array}$ & $\begin{array}{l}36.00 \\
2.9^{* * *}\end{array}$ & $\begin{array}{r}9.05 \\
1.1\end{array}$ & $\begin{array}{r}26.94 \\
1.9 *\end{array}$ \\
\hline Pct_INST in-1 $_{1}$ & $\begin{array}{l}-.90 \\
-21.5 * * *\end{array}$ & $\begin{array}{l}-.49 \\
-9.3 * * *\end{array}$ & $\begin{array}{l}-.41 \\
-6.4 * * *\end{array}$ & Pct_INST ${ }_{\text {in-1 }}$ & $\begin{array}{l}-.40 \\
-4.5^{* * *}\end{array}$ & $\begin{array}{l}-.11 \\
-1.5\end{array}$ & $\begin{array}{l}-.29 \\
-2.4^{* *}\end{array}$ & $\begin{array}{l}-.51 \\
-3.9 * * *\end{array}$ & $\begin{array}{l}-.17 \\
-2.0 * *\end{array}$ & $\begin{array}{l}-.35 \\
-2.2 * *\end{array}$ \\
\hline Spread $_{\text {in }}$ & $\begin{array}{l}.43 \\
0.1\end{array}$ & $\begin{array}{l}4.57 \\
5.4^{* * *}\end{array}$ & $\begin{array}{r}-4.14 \\
-1.1\end{array}$ & Spread $_{\text {in }}$ & $\begin{array}{l}4.12 \\
1.8 *\end{array}$ & $\begin{array}{r}2.00 \\
-1.5\end{array}$ & $\begin{array}{l}6.13 \\
2.3^{* *}\end{array}$ & $\begin{array}{r}1.81 \\
0.6\end{array}$ & $\begin{array}{r}-2.39 \\
-1.2\end{array}$ & $\begin{array}{r}4.20 \\
1.3\end{array}$ \\
\hline Log_Hilo $_{\text {in }}$ & $\begin{array}{l}2.39 \\
2.2 * *\end{array}$ & $\begin{array}{l}2.22 \\
2.6 * *\end{array}$ & $\begin{array}{l}.17 \\
0.1\end{array}$ & Log_hilo $_{\text {in }}$ & $\begin{array}{l}6.17 \\
2.7^{* * *}\end{array}$ & $\begin{array}{r}6.82 \\
2.9 * * *\end{array}$ & $\begin{array}{l}-.64 \\
-0.2\end{array}$ & $\begin{array}{r}13.61 \\
4.1 * * *\end{array}$ & $\begin{array}{r}11.04 \\
1.9 *\end{array}$ & $\begin{array}{r}2.57 \\
0.4\end{array}$ \\
\hline $\begin{array}{c}\text { Avg \# Firms/qtr } \\
\text { Avg Adj R }\end{array}$ & $\begin{array}{r}416 \\
.62\end{array}$ & $\begin{array}{r}527 \\
.28\end{array}$ & $\begin{array}{c}\mathrm{F}=1,369.4^{* * *} \\
\mathrm{~N}=53,566\end{array}$ & $\begin{array}{l}\text { Avg \# Firms/qtr } \\
\text { Panel Adj R }\end{array}$ & $\begin{array}{l}415 \\
.014\end{array}$ & $\begin{array}{l}527 \\
.004\end{array}$ & $\begin{array}{l}\mathrm{F}=32.9 * * * \\
\mathrm{~N}=53,554\end{array}$ & $\begin{array}{l}415 \\
.014\end{array}$ & $\begin{array}{l}527 \\
.005\end{array}$ & $\begin{array}{l}\mathrm{F}=21.6 * * * \\
\mathrm{~N}=53,547\end{array}$ \\
\hline
\end{tabular}

${ }^{* \star *}$ indicates statistical significance at the .10 level; ${ }^{* \star}$ at the .05 level; and ${ }^{* \star *}$ at the .01 level. 
Table 4. Determinants of Quarterly Average Abnormal Return on the Pay Date, $A R(0)_{n}$

This table presents results from estimating the following time series regression model that analyzes determinants of the quarterly profits from our three trading strategies, the quarterly average $\operatorname{AR}(0)_{n}$ for the DRIP stocks in portfolios I - III:

$$
\operatorname{AR}(0)_{n}=\beta_{0}+\beta_{1} \text { Sentiment }_{n-1}+\beta_{2} \text { Spread }_{n-1}+\beta_{3} \text { pdnd }_{n-1}+\beta_{4} \text { VIX }_{n-1}+\varepsilon_{n} .
$$

$\operatorname{AR}(0)_{n}$ is computed in two steps. First, for every day (t) in our sample, we calculate the crosssectional mean $A R(0)_{t}$ across all DRIP stocks in every portfolio (I - III) which pay dividends on that day. Second, for each quarter $(n)$, we compute the time series average, $A R(0)_{n}$, across these daily mean $A R(0)_{t}$ for the DRIP stocks in every portfolio (I - III). Sentiment $t_{n-1}$ is the sentiment index of Baker and Wurgler (2006) in the previous quarter, $n-1$. Spread ${ }_{n-1}$ is the mean daily closing spread during quarter $\mathrm{n}-1$ for the DRIP stocks in Portfolio II. pdnd $_{\mathrm{n}-1}$ is the dividend premium from Baker and Wurgler (2004) in quarter $n-1$. VIX ${ }_{n-1}$ is the CBOE Volatility Index in quarter n-1. Newey-West robust standard errors (with $L=1$ ) are used to construct the approximate t-statistics.

\begin{tabular}{|c|c|c|c|}
\hline & I. All Stocks & II. High_DY & III. Hard_Arb \\
\hline Sentiment $_{\mathrm{n}-1}$ & .03 & .18 & .30 \\
\hline t-stat & 0.4 & $2.0 *$ & $2.6 * *$ \\
\hline Spread $_{n-1}$ & .20 & .49 & .97 \\
\hline t-stat & $1.9 *$ & $2.8 * * *$ & $4.6 * * *$ \\
\hline $\operatorname{pdnd}_{n-1}$ & -.002 & .000 & .024 \\
\hline t-stat & -0.4 & 0.1 & $2.4^{* *}$ \\
\hline VIX $X_{n-1}$ & -.006 & -.032 & -.091 \\
\hline t-stat & -0.4 & -1.3 & $-2.8 * * *$ \\
\hline $\operatorname{Adj} R^{2}$ & .32 & .50 & .55 \\
\hline Overall $\mathrm{F}$ & $7.4 * * *$ & $14.4 * * *$ & $17.3 * * *$ \\
\hline
\end{tabular}




\section{Appendix A. Excerpts from Dividend Reinvestment Plans (DRIPs)}

The following excerpts exemplify the relevant details common in DRIP documentation.

\section{H.B. Fuller Company DRIP Document (2011), selected excerpts:}

"As the Plan Administrator, Wells Fargo Shareowner Services, a division of Wells Fargo Bank, N.A., (the Plan 'Administrator') offers investors a simple and convenient method of investing in H.B. Fuller Company common stock. The Plan Administrator will apply all of the participants' designated dividends ... to purchase whole and fractional shares acquired under the Dividend Reinvestment Plan. Such purchases may be made on any securities exchange where such shares are traded, in the over-the-counter market or in negotiated transactions, and may be on such terms as to price, delivery and otherwise as the Plan Administrator may determine.

Dividends are invested as soon as administratively possible on or following the dividend payable date, generally within five (5) trading days. In the case of each purchase, the price at which the Plan Administrator shall be deemed to have acquired H.B. Fuller common stock for the participant's account shall be the weighted average price of all shares purchased plus any per share fees. Depending on the number of shares being purchased and current trading volumes in the shares, purchases may be executed in multiple transactions that may occur on more than one day."

\section{Carnival Corporation DRIP Document (2007), selected excerpts:}

"The shares of Carnival Corporation common stock purchased under the (Dividend Reinvestment) Plan may be newly issued shares or shares purchased for participants in the open market, at Carnival Corporation's option. The Plan currently provides that shares purchased for participants with reinvested dividends will be purchased at fair market value, as determined in the Plan. 
WHO ADMINISTERS THE PLAN?

Computershare Trust Company, N.A. (the 'Agent'), a bank unaffiliated with Carnival Corporation, administers the Plan. The Agent arranges for the custody of share certificates, keeps records, sends statements of account to participants, and makes purchases of shares of Carnival Corporation common stock under the Plan for the accounts of participants. The Agent will send each participant a statement of his or her account under the Plan as soon as practicable following each purchase of shares of Carnival Corporation common stock. Each statement will show (a) any dividends credited; (b) plan shares purchased and fractional shares allocated; (c) the cost per share of the purchased shares and fractional shares; (d) the number of whole shares for which certificates have been issued, if any; and the beginning and ending balances of whole shares and fractional shares ... The Agent will also serve as custodian of shares purchased under the Plan to protect participants from loss, theft or destruction of stock certificates.

\section{WHAT IS THE SOURCE OF SHARES PURCHASED UNDER THE PLAN?}

Shares purchased under the Plan will come from the authorized and unissued shares of the Carnival Corporation common stock or from shares purchased on the open market by the Agent, as determined by Carnival Corporation.

With respect to any open market purchases made under the Plan, the Agent will have full discretion as to all matters relating to purchases, including determination of the number of shares, if any, to be purchased on any day, the time of day, the price paid for such shares, the markets in which such shares are to be purchased ...

\section{WHEN WILL FUNDS BE INVESTED UNDER THE PLAN?}

If shares are purchased from Carnival Corporation, the purchases will be made on the dividend payment date and such shares will be credited to participants' accounts on the dividend 
payment date. If shares are to be purchased in the open market, the Agent is to use its best efforts to apply all funds received by it to the purchase of shares within 30 days of the receipt of such funds from Carnival Corporation ...

\section{WHAT IS THE PURCHASE PRICE OF THE SHARES?}

If the Carnival Corporation common stock is purchased from Carnival Corporation, the price per share ... will be the closing price for the Carnival Corporation common stock on the NYSE Composite Tape on the dividend payment date, as reported in THE WALL STREET JOURNAL or other authoritative source. The price per share for open market purchases will be the weighted average price paid by the Agent for all shares of Carnival Corporation common stock purchased by it for participants in the Plan through negotiation with the seller. No share of Carnival Corporation common stock will be purchased at a price in excess of current market prices at the time of purchase."

\section{Appendix B. Time Series Means of Cross-Sectional Medians for the Variables}

In this appendix we duplicate the analysis in Table 1, but we analyze the average behavior of the cross-section medians of the main variables each quarter, rather than the cross-sectional means. This evidence is presented in Table B.1, and is generally robust with respect to the analysis in Table 1. This outcome indicates that our main results are not due to outliers.

\section{Appendix C. The Intraday Price Pattern on the Dividend Pay Date}

In this appendix we examine the intraday pattern in price movements on the dividend pay date, for the subsets of DRIP stocks in Portfolios I - III. This analysis reveals whether investors (or their transfer agents) tend to exert price pressure at certain times on the day that dividend funds are distributed. We analyze intraday midquotes at five-minute intervals for the first and last 30 
minutes of trading on day 0 , and at thirty-minute intervals during the rest of this trading day. We also analyze midquotes during the last three hours of the previous trading day, on day $-1 .{ }^{28}$

For each stock analyzed, we begin by computing the ratio of the midquote at every intraday time interval (T) to the closing midquote on day 0. For each portfolio analyzed, the average intraday price pattern is then calculated in two stages. First, for every quarter in our sample period, 1996 through 2009, we calculate the cross-sectional average price ratio across dividend events at every intraday time interval (T) during days -1 and 0 . Second, we compute the time series means of these quarterly cross-sectional average intraday price ratios, across all quarters in the sample.

Results are plotted in Figure C.1 for the DRIP stocks in Portfolios I - III. For each successive subset of DRIP stocks, the mean intraday pattern begins at a lower price point, and thereby reflects a larger increase on day 0 . The magnitude of the price increase from the close on day -1 to the close on day 0 ranges from 5 basis points (bp) for the DRIP stocks in Portfolio I (i.e., 1 - .9995), to $40 \mathrm{bp}$ for the DRIP stocks in Portfolio II (i.e., 1 - .9960), to 85 bp for those in Portfolio III (i.e., 1 - .9915). For portfolio I, this evidence suggests a smaller close-to-close return than is documented in Table 1 and Figure 2. For portfolios II and III, this evidence closely corresponds to the results in Table 1 and Figure 2. These results indicate that each successive subset of DRIP stocks has a larger mean abnormal close-to-close return on day 0.

In Figure C.1, these intraday patterns of price movements reveal how the price increase transpires throughout the dividend pay date, for these portfolios of DRIP stocks. First, prices are roughly flat during the last three hours of trading on day -1 , before rising 10-15 bp in the last five minutes of trading. Then, for portfolios II and III, the mean opening midquote on day 0 is within 
a few basis points of the closing price on day -1, indicating that the mean overnight return before day 0 is also flat for these portfolios of DRIP stocks. This result suggests that transfer agents do not focus their buying at the open on the dividend pay date.

After the open on day 0 , the average price for each portfolio increases gradually throughout the trading day, and then accelerates during the last five minutes of trading. It is noteworthy that a large portion of the variation in the mean close-to-close return on day 0 , across the DRIP stocks in Portfolios I - III, appears during the last five minutes of trading. Figure C.1 reveals an average 5-minute price increase at the close on day 0 that ranges from roughly $10 \mathrm{bp}$ for Portfolio I to around $25 \mathrm{bp}$ for Portfolio III. Together, this evidence suggests that transfer agents gradually buy these stocks throughout day 0 , and then perhaps accelerate their purchase orders just before the close in an apparent attempt to complete as much of their DRIP purchases as possible on the pay date.

\section{Appendix D. Extended Analysis of Time Series of Quarterly Profits}

This Appendix presents two Figures and a Table that extend the analysis of the time series of profits generated from our three proposed trading strategies. Figure D.1 plots the time series of quarterly mean actual profits from our three strategies, without subtracting the market return, Return $(0)_{n}$. Figure D.2 plots the same three quarterly series of mean actual profits, with and without subtracting transaction costs, Return $(0)_{n}$ - TC. Table B.1 presents Fama-French regression analysis of the daily stream of average abnormal profits from our three strategies, $\operatorname{AR}(0)_{t}$. 
Table B.1. Summary Statistics: Time Series Means of Cross-Sectional Medians for the Main Variables

This table reproduces the presentation in Table 1, but summarizes the median values of the main variables. As in Table 1 , Panels $A-C$ give the results for three different portfolios of stocks selected each quarter, with and without DRIPs. Panel A provides the results for Portfolio I (All dividend-paying stocks), while Panels B and C present the results for Portfolio II (High_DY) and Portfolio III (Hard_Arb), which are described in the text. In every Panel we provide five sets of results for: (i) all stocks in that portfolio, (ii) DRIP stocks, (iii) Non-DRIP stocks, (iv) the difference of means across DRIP and NonDRIP stocks, and (v) the analogous results for a subset of matched pairs within every portfolio. Unlike Table 1, this table presents the time series means of the quarterly cross-sectional medians for all variables. First, every quarter we compute the cross-sectional median for each variable. Second, we compute the time series mean of these cross-sectional medians across all quarters in the sample. We then use the standard error of this time series mean to construct the t-statistics. Column (7) provides the difference of the the time series means of the quarterly cross-sectional medians across the DRIP versus non-DRIP subsamples, for each portfolio. Column (10) presents the time series mean of the quarterly cross-sectional differences across the medians for the matched pairs of DRIP stocks versus non-DRIP stocks in each portfolio.

\begin{tabular}{|c|c|c|c|c|c|c|c|c|c|c|}
\hline Panel A. & \multicolumn{2}{|c|}{$\begin{array}{c}\text { Portfolio I. All Stocks } \\
\begin{array}{cc}(1) & (2) \\
\text { median } & \text { (t-stat) } \\
\end{array}\end{array}$} & $\begin{array}{l}\text { I. All D } \\
\text { (3) } \\
\text { median }\end{array}$ & $\begin{array}{l}\text { Stocks } \\
\text { (4) } \\
\text { (t-stat) }\end{array}$ & $\begin{array}{l}\text { I. All Non } \\
\text { (5) } \\
\text { median }\end{array}$ & $\begin{array}{l}\text { IP Stocks } \\
\text { (6) } \\
\text { (t-stat) }\end{array}$ & $\begin{array}{l}\text { I. Diff of Medians } \\
\begin{array}{c}(3)-(5) \\
(7)\end{array} \\
\text { DRIP - Non-DRIP }\end{array}$ & $\begin{array}{c}(8) \\
\text { DRIP }\end{array}$ & $\begin{array}{l}\text { Matched F } \\
\text { (9) } \\
\text { Non-DRIP }\end{array}$ & $\begin{array}{l}\text { (10) } \\
\text { Median Diff }\end{array}$ \\
\hline \# firms per qtr & 1,418 & 59.0 & 535 & 37.5 & 883 & 47.5 & $-348 * * *$ & 286 & 286 & 0 \\
\hline $\operatorname{AR}(-3)_{\text {in }} \%$ & .00 & 0.1 & .03 & 1.7 & -.02 & -1.0 & $.05 *$ & .02 & .01 & .00 \\
\hline $\operatorname{AR}(0)_{\text {in }} \%$ & .07 & 3.7 & .16 & 7.1 & .01 & .4 & $.15^{* * *}$ & .17 & .02 & $.17^{* * *}$ \\
\hline $\operatorname{CAR}(0,+1)_{\text {in }} \%$ & .11 & 3.1 & .21 & 4.9 & .04 & 1.2 & $.17^{* * *}$ & .24 & .07 & $.16^{* * *}$ \\
\hline $\operatorname{CAR}(+2,+10)_{\text {in }} \%$ & -.47 & -4.7 & -.40 & -4.5 & -.54 & -4.5 & .14 & -.40 & -.33 & -.11 \\
\hline $\operatorname{CAR}(0,+10)_{\text {in }} \%$ & -.26 & -2.0 & -.15 & -1.3 & -.35 & -2.5 & .21 & -.08 & -.17 & .04 \\
\hline$A R(e x-d i v)_{\text {in }} \%$ & .19 & 8.8 & .12 & 5.6 & .23 & 9.8 & $-.11 * * *$ & .18 & .19 & .00 \\
\hline AR(0) Mean Diff & -.08 & -4.1 & .05 & 2.4 & -.19 & -8.3 & $.25^{* * *}$ & .04 & -.14 & $.19^{* * *}$ \\
\hline Size $_{\text {in }}$ (millions) & $\$ 658$ & 21.8 & $\$ 2,363$ & 21.0 & $\$ 321$ & 18.2 & $\$ 2,041 * * *$ & $\$ 1,078$ & $\$ 1,136$ & $-\$ 51 * * *$ \\
\hline Div_Yield ${ }_{\text {in }} \%$ & .55 & 46.3 & .62 & 49.5 & .50 & 45.5 & $.13^{* * *}$ & .59 & .46 & .10 \\
\hline Pct_Inst ${ }_{\text {in-1 }} \%$ & 51.05 & 34.8 & 60.28 & 52.0 & 41.91 & 23.7 & $18.37^{* * *}$ & 57.62 & 57.81 & $-.44^{* * *}$ \\
\hline Spread $_{\text {in }} \%$ & .86 & 8.9 & .61 & 8.4 & 1.13 & 9.1 & $-.51 * * *$ & .76 & .74 & .04 \\
\hline $\log _{-} H_{i L o}$ in $\%$ & 2.64 & 19.3 & 2.48 & 18.7 & 2.76 & 19.3 & -.29 & 2.54 & 2.73 & $-.17^{* * *}$ \\
\hline $\mathrm{CSHR}_{\text {in }} \%$ & 4,316 & 55.1 & 13,036 & 62.3 & 1,625 & 59.8 & $11,411 * * *$ & 6,863 & 2,619 & $2,975 * * *$ \\
\hline Firm_Age $_{\text {in }} \%$ & 18.54 & 78.9 & 29.57 & 64.4 & 13.14 & 66.3 & $16.43^{* * *}$ & 28.22 & 15.82 & $7.58^{* * *}$ \\
\hline
\end{tabular}

* indicates significance at the .10 level; ${ }^{* *}$ at the .05 level; and ${ }^{* * *}$ at the .01 level, for the mean difference t-test in the last column. 
Table B.1, continued

\begin{tabular}{|c|c|c|c|c|c|c|c|c|c|c|}
\hline \multirow{2}{*}{ Panel B. } & \multirow{2}{*}{\multicolumn{2}{|c|}{$\begin{array}{l}\text { Portfolio II. High_DY } \\
\text { median } \\
\end{array}$}} & \multicolumn{2}{|c|}{ DRIP Stocks in II. } & \multicolumn{2}{|c|}{ Non-DRIP Stocks in II. } & \multirow{2}{*}{$\begin{array}{l}\text { II. Diff of Medians } \\
\text { DRIP - Non-DRIP }\end{array}$} & \multicolumn{3}{|c|}{ II. Matched Pairs } \\
\hline & & & median & (t-stat) & median & (t-stat) & & DRIP & Non-DRIP & Median Diff \\
\hline \# firms per qtr & 567 & 59.0 & 258 & 30.3 & 310 & 52.3 & $-52 * * *$ & 81 & 81 & 0 \\
\hline$A R(-3)_{\text {in }} \%$ & .06 & 2.3 & .08 & 3.5 & .03 & 1.2 & .05 & .10 & .07 & .00 \\
\hline $\operatorname{AR}(0)_{\text {in }} \%$ & .21 & 7.3 & .31 & 7.7 & .10 & 3.5 & $.21 * * *$ & .35 & .09 & $.31 * * *$ \\
\hline $\operatorname{CAR}(0,+1)_{\text {in }} \%$ & .29 & 5.4 & .38 & 5.7 & .19 & 3.8 & $.19 * *$ & .47 & .14 & $.31 * * *$ \\
\hline $\operatorname{CAR}(+2,+10)_{\text {in }} \%$ & -.69 & -5.3 & -.63 & -5.4 & -.77 & -5.3 & .14 & -.69 & -.56 & -.20 \\
\hline $\operatorname{CAR}(0,+10)_{\text {in }} \%$ & -.28 & -1.8 & -.17 & -1.1 & -.45 & -2.6 & .28 & -.06 & -.34 & .10 \\
\hline ex-div $A R(0)_{\text {in }} \%$ & .31 & 9.9 & .17 & 5.5 & .45 & 12.3 & $-.28 * * *$ & .28 & .36 & $-.09 * *$ \\
\hline$A R(0)$ Mean Diff & -.02 & -0.5 & .16 & 4.2 & -.25 & -6.3 & $.41^{* * *}$ & .13 & -.19 & $.32^{* * *}$ \\
\hline Size $_{\text {in }}$ (millions) & $\$ 366$ & 22.4 & $\$ 1,688$ & 16.6 & $\$ 130$ & 21.7 & $\$ 1,558 * * *$ & $\$ 489$ & $\$ 505$ & $\$ 2$ \\
\hline Div_Yield $_{\text {in }} \%$ & .91 & 42.9 & .93 & 48.1 & .89 & 39.0 & .03 & .92 & .88 & $.03 * * *$ \\
\hline Pct_Inst ${ }_{\text {in-1 }} \%$ & 35.72 & 29.7 & 50.14 & 41.2 & 22.43 & 21.0 & $27.7 * * *$ & 36.80 & 37.38 & 1.09 \\
\hline Spread $_{\text {in }} \%$ & 1.01 & 9.6 & .67 & 8.6 & 1.61 & 10.7 & $-.94 * * *$ & .98 & .99 & .01 \\
\hline Log_HiLo in $\%$ & 2.50 & 17.0 & 2.34 & 16.7 & 2.68 & 17.0 & -.34 & 2.44 & 2.61 & $-.14 * * *$ \\
\hline $\mathrm{CSHR}_{\text {in }} \%$ & 6,140 & 46.6 & 16,956 & 40.6 & 1,348 & 32.9 & $15,608 * * *$ & 7,535 & 2,617 & $3,618 * * *$ \\
\hline Firm_Age ${ }_{\text {in }} \%$ & 20.39 & 51.3 & 29.76 & 58.4 & 12.10 & 66.1 & $17.67 * * *$ & 25.82 & 14.45 & $7.92 * * *$ \\
\hline \multirow{2}{*}{ Panel C. } & \multirow{2}{*}{\multicolumn{2}{|c|}{$\begin{array}{c}\text { Portfolio III. Hard_Arb } \\
\text { median }\end{array}$}} & \multirow{2}{*}{\multicolumn{2}{|c|}{$\begin{array}{l}\text { DRIP Stocks in III. } \\
\text { median } \quad \text { (t-stat) }\end{array}$}} & \multirow{2}{*}{\multicolumn{2}{|c|}{$\begin{array}{l}\text { Non-DRIP Stocks in III. } \\
\text { median } \quad \text { (t-stat) }\end{array}$}} & III. Diff of Medians & \multicolumn{3}{|c|}{ III. Matched Pairs } \\
\hline & & & & & & & DRIP - Non-DRIP & DRIP & Non-DRIP & Median Diff \\
\hline \# firms per qtr & 207 & 49.3 & 41 & 14.5 & 166 & 33.7 & $-124 * * *$ & 19 & 19 & 0 \\
\hline $\operatorname{AR}(-3)_{\text {in }} \%$ & .07 & 2.0 & .25 & 3.8 & .04 & 1.0 & $.21^{* * *}$ & .33 & .14 & .18 \\
\hline $\operatorname{AR}(0)_{\text {in }} \%$ & .28 & 5.3 & .62 & 6.4 & .17 & 3.5 & $.45^{* * *}$ & .74 & .16 & $.58 * * *$ \\
\hline $\operatorname{CAR}(0,+1)_{\text {in }} \%$ & .41 & 5.0 & .75 & 6.2 & .29 & 4.0 & $.46 * * *$ & .72 & .37 & $.42 * *$ \\
\hline $\operatorname{CAR}(+2,+10)_{\text {in }} \%$ & -1.02 & -4.9 & -1.25 & -4.8 & -.90 & -4.6 & -.35 & -1.47 & -.34 & $-1.07^{* * *}$ \\
\hline $\operatorname{CAR}(0,+10)_{\text {in }} \%$ & -.45 & -1.8 & -.44 & -1.3 & -.51 & -2.1 & .07 & -.46 & -.12 & -.70 \\
\hline ex-div $A R(0)_{\text {in }} \%$ & .55 & 12.3 & .49 & 7.2 & .55 & 12.0 & -.07 & .74 & .50 & .22 \\
\hline$A R(0)$ Mean Diff & -.16 & -2.9 & .13 & 1.3 & -.28 & -5.3 & $.41^{* * *}$ & .09 & -.40 & $.36^{* *}$ \\
\hline Size $_{\text {in }}$ (millions) & $\$ 72$ & 22.8 & $\$ 155$ & 22.7 & $\$ 63$ & 19.9 & $\$ 92 * * *$ & $\$ 111$ & $\$ 107$ & $\$ 3 * *$ \\
\hline Div_Yield in $\%$ & .91 & 40.9 & .97 & 47.7 & .90 & 39.3 & $.07^{* *}$ & .96 & .89 & $.04 *$ \\
\hline Pct_Inst ${ }_{\text {in-1 }} \%$ & 11.90 & 24.4 & 17.60 & 26.3 & 10.81 & 22.3 & $6.79^{* * *}$ & 14.29 & 14.62 & -.71 \\
\hline Spread $_{\text {in }} \%$ & 2.50 & 13.9 & 1.92 & 11.2 & 2.72 & 14.1 & $-.79 * * *$ & 2.29 & 2.17 & $.07^{* *}$ \\
\hline Log_HiLo in $\%$ & 2.73 & 19.6 & 2.61 & 20.1 & 2.80 & 19.2 & -.19 & 2.51 & 2.59 & -.03 \\
\hline $\mathrm{CSHR}_{\text {in }} \%$ & 1,134 & 41.9 & 3,109 & 16.0 & 830 & 46.0 & $2,279 * * *$ & 2,113 & 1,433 & $704^{* *}$ \\
\hline Firm_Age $_{\text {in }} \%$ & 11.05 & 49.3 & 17.41 & 34.7 & 10.04 & 39.8 & $7.37^{* * *}$ & 16.38 & 10.52 & $4.85^{* * *}$ \\
\hline
\end{tabular}




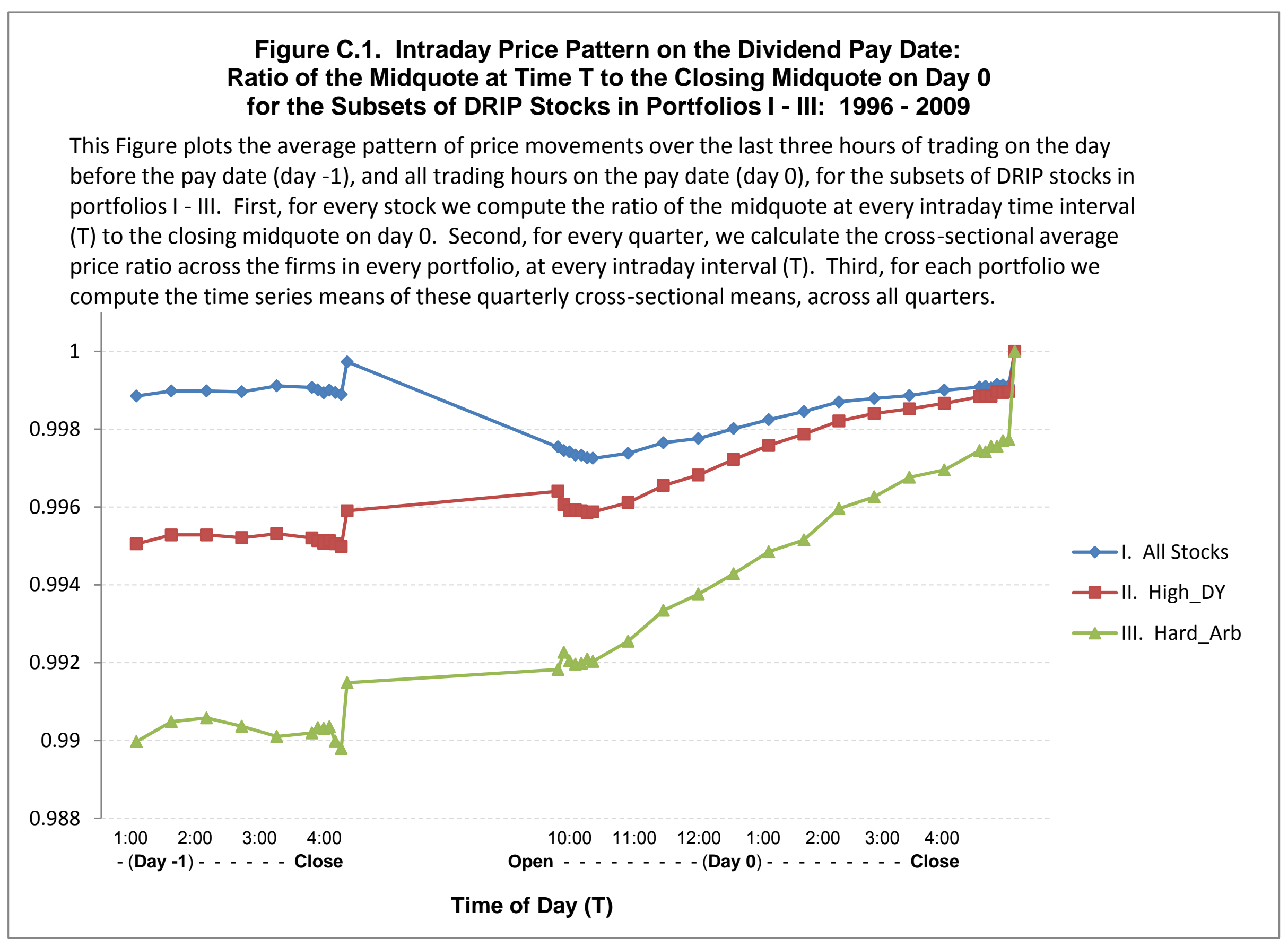




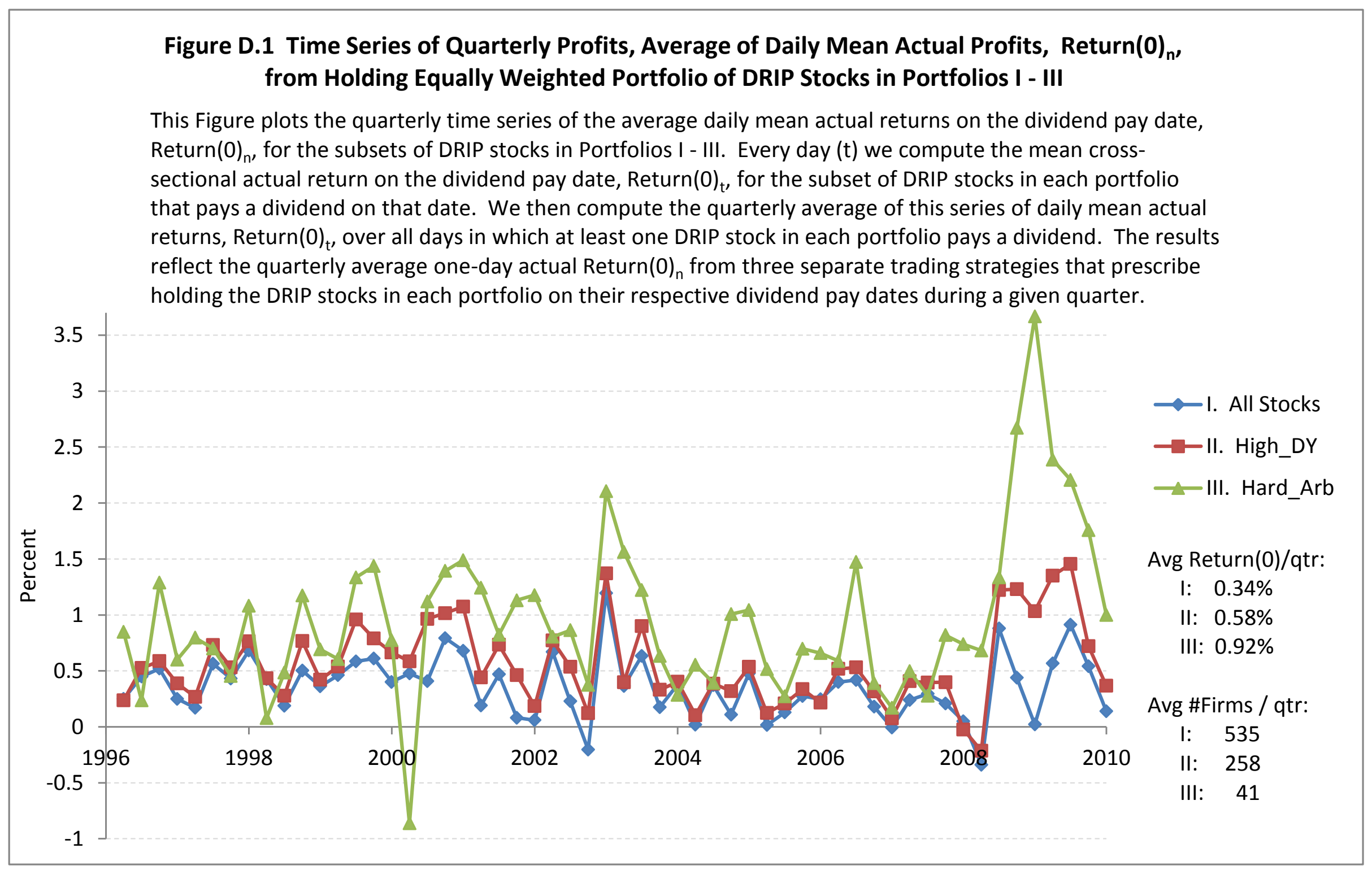


Figure D.2 Quarterly Average Gross Actual Profit, Return $(0)_{n}$, and Net Profit, Return $(0)_{n}$ - TC

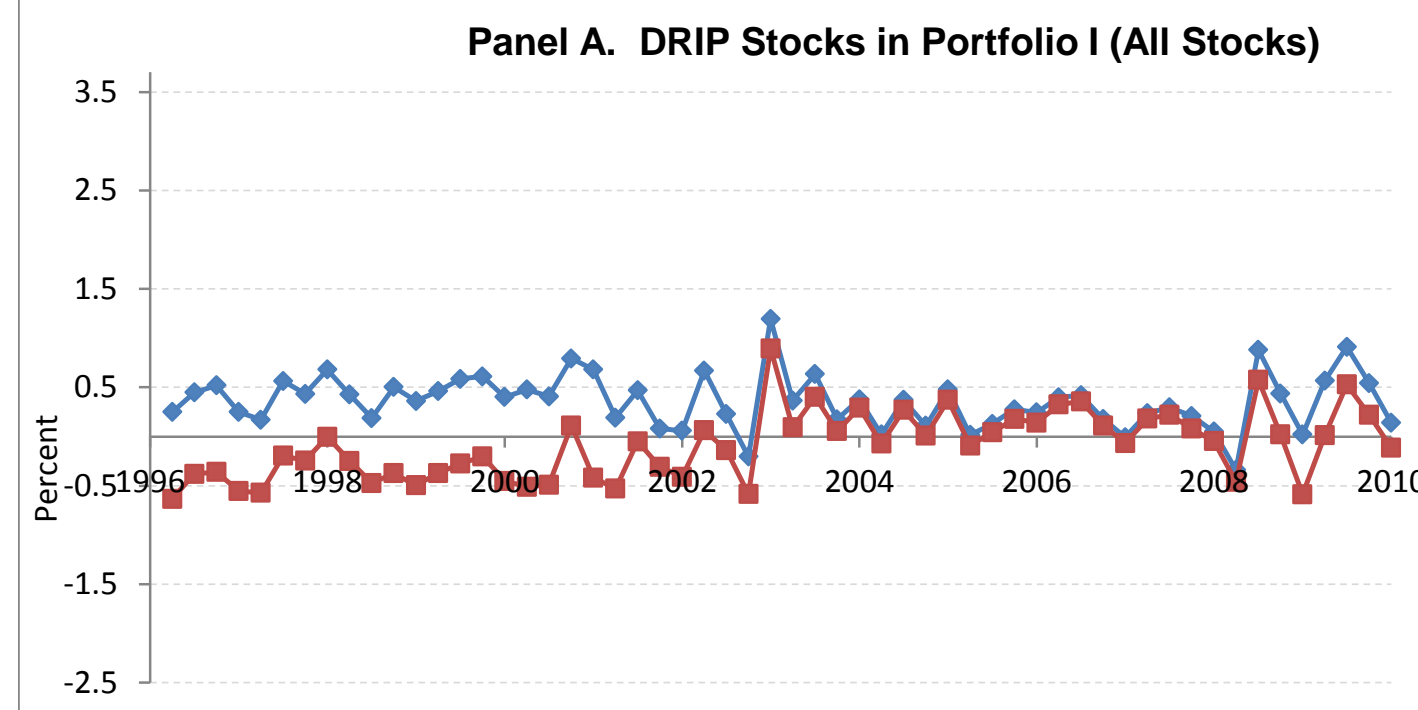

$\sim$ Return(0)

$\rightarrow$ Return(0) - TC

Entire Sample:

(Avg / qtr)

535 Stocks

Return(0) $=0.36 \%$

Return(0)-TC $=-0.09 \%$

Since 2001.Q2:

469 Stocks

Return(0) $=0.30 \%$

Return(0)-TC $=0.07 \%$

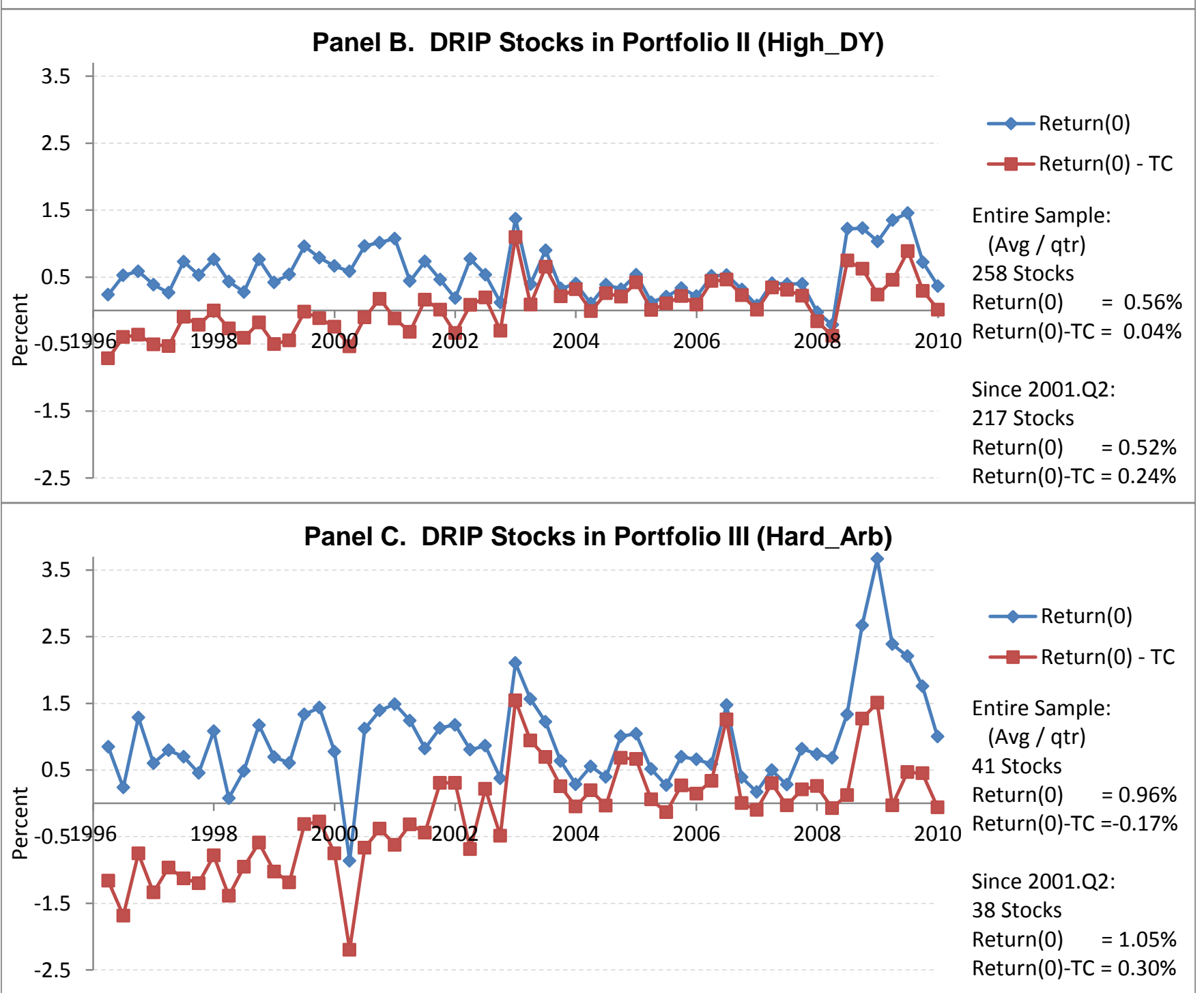


Table D.1. Fama-French Regressions on Daily Mean Market-Adjusted Abnormal Returns, $A R(0)_{t}$, from Three Trading Strategies that Prescribe Holding the DRIP Stocks in Portfolios I - III that Pay Dividends on any Date

This table presents the results from estimating a Fama-French 3 or 4-factor model to analyze the mean daily market-adjusted abnormal returns on the dividend pay date, $\mathrm{AR}(0)_{\mathrm{t}}$, from three trading strategies that prescribe holding the subset of DRIP stocks in each portfolio (I - III) that pay dividends on any given date $(\mathrm{t})$ :

$$
\operatorname{AR}(0)_{t}=\alpha+\beta_{1}\left(R_{m}-R_{f}\right)_{t}+\beta_{2} H_{M L}+\beta_{3} S M B B_{t}+\beta_{4} U_{M D}+\varepsilon_{t} .
$$

First, we construct portfolios I - III each quarter, as described in the text. Second, every quarter we compute the daily market-adjusted abnormal return on the dividend pay date for each stock, $A R(0)_{i t}$, by subtracting the daily return on the S\&P 500 index from the daily return for that stock (i). Third, we compute the mean daily abnormal return on the pay date, $A R(0)_{t}$, across all DRIP stocks in each portfolio that pay dividends on any given date $(t)$ during our sample period. The resulting time series of daily mean abnormal returns, $\operatorname{AR}(0)_{t}$, represents the daily return to our trading strategy that is analyzed in the above Fama-French regression model. Newey-West robust standard errors are used to construct the t-statistics.

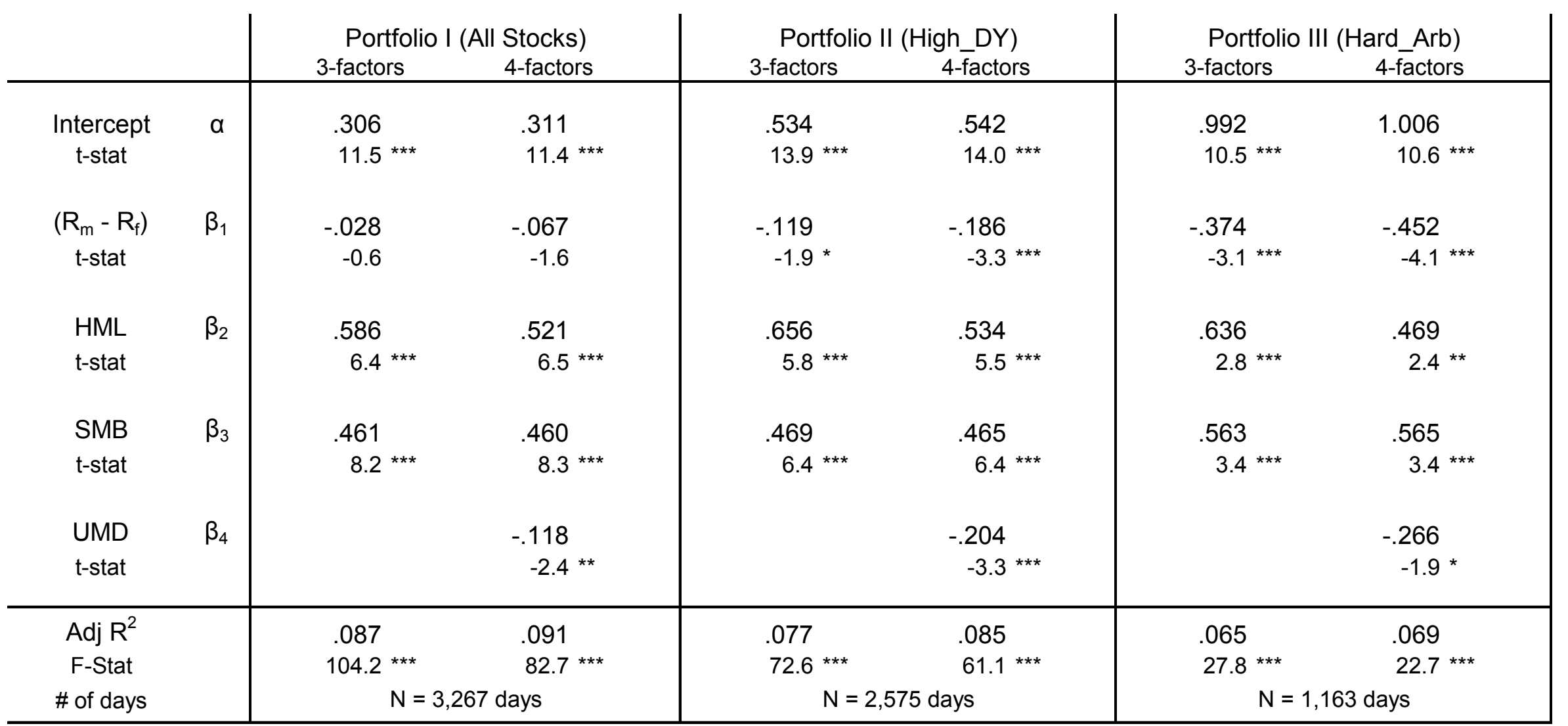

* indicates significance at the .10 level; ${ }^{* *}$ at the .05 level; and ${ }^{* * *}$ at the .01 level. 